Research Article

\title{
Wear Properties of TiC-Reinforced Co50 Composite Coatings from Room Temperature to High Temperature
}

\author{
Nga Thi-Hong Pham $(i)$ and Van-Thuc Nguyen \\ Mechanical Engineering Faculty, HCMC University of Technology and Education, 1 Vo Van Ngan St., Thu Duc District, \\ Ho Chi Minh City 700000, Vietnam \\ Correspondence should be addressed to Nga Thi-Hong Pham; hongnga@hcmute.edu.vn
}

Received 27 May 2020; Revised 3 July 2020; Accepted 4 July 2020; Published 6 August 2020

Academic Editor: Pavel Lejcek

Copyright (c) 2020 Nga Thi-Hong Pham and Van-Thuc Nguyen. This is an open access article distributed under the Creative Commons Attribution License, which permits unrestricted use, distribution, and reproduction in any medium, provided the original work is properly cited.

\begin{abstract}
In this paper, the laser cladding is created by using Co50 powder and $\mathrm{TiC}$ mixture, covering a $\mathrm{H} 13$ hot-working steel substrate. The samples are analyzed by the hardness test, XRD, SEM, and friction test to identify the forming phases, microhardness distribution, and wear-resistant characteristics. The results indicated that hardness reduces from the coating zone to the substrate, achieving the highest value at the coating zone. Increasing the content of TiC results in improving the coating hardness. The coatings with $10 \%-$ $20 \% \mathrm{TiC}$ show high-quality surface morphology and macrograph. With $30 \% \mathrm{TiC}$, the hardness obtains a higher hardness, but the surface appears to crack. The microstructures of the coatings present a well-mixed and well-distribution of the TiC particle on the Co matrix. The friction coefficient of $\mathrm{H} 13$ steel and Co50 coating reaches the maximum value when the load is $50 \mathrm{~N}$ and mostly decreases with the increase in the load. The wear rates of $\mathrm{H} 13$ steel and Co50 coatings mainly increase with the increase in the load. The temperature has a greater influence on the friction coefficient of the Co50 coating. However, the temperature has a small effect on the friction coefficient of the $20 \% \mathrm{TiC}$ coating. The wear resistance of $20 \% \mathrm{TiC}$ coating is higher than that of $\mathrm{H} 13$ steel, Co50 coating, and $10 \% \mathrm{TiC}$ composite coating. At room temperature, the wear mechanism of the coating is mainly brittle spalling, adhesive wear, and ploughing. At $700^{\circ} \mathrm{C}$, the wear mechanism is mostly oxidation wear and fatigue wear. After laser cladding, the service life of the coated surface could be greatly improved. The Co $+20 \% \mathrm{TiC}$ coating has high hardness and wear resistance.
\end{abstract}

\section{Introduction}

Most machinery failures are caused not by fractures but by wear and damage of friction surfaces in dynamic joints. More than half of the fuel used to run cars, locomotives, and other vehicles is essential to overcome the resistance caused by friction in the engine parts. Similarly, the process of using hot-work mold steels requires the surface must have the same strength and ductility, especially resistance to wear and heat fatigue at high temperatures. Currently, there are many advanced methods of improving surface quality that have been applied, such as carburizing, nitriding, and nitrocarburizing. In general, the harder the material is, the more the brittleness. Researchers are trying to find an ideal material that has both high hardness and high thermal and flexural strength. The machining methods such as milling, lathing, electrical discharge machining, and electroplating change the structure and physical and mechanical features of the surface layers. Recently, surface modification technologies are rapidly developed and applied to create a hard surface while still preserving the flexibility of the substrate. One of those techniques is coating the surface with high hardness and small abrasion coefficient on materials with high flexural strength.

Friction abrasion is a complex process, influenced by many factors. Especially at high temperatures, in addition to the oxygen process, the hardness and durability will be significantly reduced, and thermal expansion will change the organization of the coating. These phenomena are complex but common forms of damage [1-3]. When using hotworking molds, the surface is required to have a hightemperature strength and toughness, especially the wear 
resistance thermal fatigue performance at high temperature. For the surface layer, its wear friction is a complex process, which is affected by many factors such as load, sliding speed, ambient temperature, type of friction pair, and surrounding medium. Therefore, it is very important to study the hightemperature friction and wear properties of the surface layer. Under high-temperature conditions, as the temperature of the mold increases, the degree of oxidation and thermal expansion increase. Moreover, the hardness and strength decrease results in changing the microstructure of the mold. It is an extremely complex form of failure, which makes the wear resistance of the material reduce dramatically. In the laser cladding field, a great number of researches have been reported on the wear resistance and corrosion resistance of coating alloy layers. Recently, the friction and wear properties of cladding layers have been studied at room temperature. However, there is not much research on friction and wear properties and its corresponding microstructure at high temperatures. Especially, the effect of adding $\mathrm{TiC}$ in laser cladding has not been reported yet [4-7]. Therefore, a study on the high-temperature friction and wear performance of the cladding layer is particularly important.

In recent years, laser cladding (LC) method has been considered as an advanced material surface modification method, being developed at rapid speed. LC technology is proved to be useful in repairing and restoring the worn surfaces, especially surfaces with a large size [8-10]. In this LC method, melting techniques of metal/carbide base layer have been strongly developed in recent years to improve the wear resistance of the base material. In particular, the coating of self-melting Co alloy can improve the oxidation resistance and wear resistance on the surface of the material $[7,11-15]$.

Co-based alloy has excellent high-temperature performance, high-temperature wear resistance, high-temperature corrosion resistance, good thermal strength, and cold and hot fatigue performance. In addition, it has good thermal conductivity and low thermal expansion coefficient and good performance in shock resistance, creep resistance, wear resistance, and corrosion resistance. It still has good oxidation resistance and abrasion resistance above $600^{\circ} \mathrm{C}$, still maintaining a high hardness at $800^{\circ} \mathrm{C}$, and having a good antioxidation performance at $1080^{\circ} \mathrm{C}$, which are very suitable for hot work of die steel. Xiao-hong et al. and other studies have shown that the H13 hot-work die steel surface after laser cladding Co-based alloy significantly improves the high-temperature hardness and thermal fatigue resistance of the die [16]. This result proves that the surface laser cladding technology can strengthen the mold surface, or the repair of the old mold has broad application prospects. Qian et al. and others performed laser cladding on the surface of $\mathrm{H} 13$ die steel and successfully prepared a Co-based alloy coating [10]. The coating and H13 steel substrate showed good metallurgical bonding characteristics. After laser cladding, the H13 steel base, the surface hardness, and wear resistance of the material have been significantly improved [3]. Zhao et al. indicate that the Co-based coating and the substrate showed a good metallurgical combination. After the thermal fatigue test, the Co-based coating still maintained high hardness and high-temperature cracking, which proved that Co-based coating has good wear resistance [4].

Nowadays, a higher quality is required for the function of coatings, and normally, a single material cannot meet. Recently, the addition of $\mathrm{WC}, \mathrm{B}_{4} \mathrm{C}, \mathrm{SiC}, \mathrm{Cr}_{2} \mathrm{C}_{3}, \mathrm{TiN}$, and other ceramic particles to the Co-based alloy can change the structure of the Co-based alloy and significantly improve the performance of the coating. Zhiyuan et al. reported a cladding Co-based alloy coating and TiN/Co-based composite coating on the surface of low-carbon steel. The results show that TiN has a significant improvement effect on the structure of the cladding layer, which promotes the refinement of its structure, and the dendrite is equiaxed. Crystal transformation can also significantly improve the microhardness and wear resistance of Co-based alloy coatings [17]. Song-hua et al. studied the laser cladding of Co60 and the addition of $\mathrm{Cr}_{2} \mathrm{C}_{3} / \mathrm{Co}$ coatings with different contents of $\mathrm{Cr}_{2} \mathrm{C}_{3}$ (wt.\%) on the surface of low-carbon steel. The study found that the hardness, wear resistance, and high-temperature resistance of $\mathrm{Cr}_{2} \mathrm{C}_{3} / \mathrm{Co}$ coatings. The oxidation and corrosion resistance are significantly improved than Co60 coating [18]. Moreover, the prior study also shows laser cladding Co55 coating on the surface of lowcarbon steel and adding $20 \% \mathrm{~B}_{4} \mathrm{C}$ (vol.\%) coating $\left(\mathrm{B}_{4} \mathrm{C} / \mathrm{Co}\right)$. The results show that the added $\mathrm{B}_{4} \mathrm{C}$ significantly refines the dendrite structure of the coating. Compared with the Co55 coating, the $\mathrm{B}_{4} \mathrm{C} / \mathrm{Co}$ coating has significantly improved microhardness and wear resistance [19]. However, comprehensive studies by Huang et al. and others found that, in liquid steel, $\mathrm{SiC}$ is extremely unstable and easily reacts with steel, and $\mathrm{Cr}_{2} \mathrm{C}_{3}$ is easily soluble in the steel matrix. However, WC and $\mathrm{Mo}_{2} \mathrm{C}$ can react with the matrix to form new carbide phases, such as $\mathrm{M}_{6} \mathrm{C}$ and $\mathrm{MC}$ carbide. $\mathrm{Al}_{2} \mathrm{O}_{3}$ has good chemical stability, but its wettability with steel is not good. It is difficult to be wetted by liquid steel, and it cannot be evenly dispersed in liquid steel. Above $900^{\circ} \mathrm{C}$, AlN particles dissolve into austenite. In this process, austenite grains will grow rapidly, and particles such as $\mathrm{TiB}_{2}$ and $\mathrm{B}_{4} \mathrm{C}$ are only suitable for the preparation of iron-based powder metallurgy materials. The crystal structure of $\mathrm{NbC}, \mathrm{TiC}, \mathrm{VC}$, and $\mathrm{ZrC}$ particles are all face-centered cubic, thermodynamically stable, and suitable for steel materials [8].

Among carbide ceramic particles, TiC has excellent comprehensive properties with high hardness $(3200 \mathrm{HV})$, good thermal stability, a high melting point of $3150^{\circ} \mathrm{C}$, and good resistance to high-temperature oxidation. In addition, TiC has a small coefficient of thermal expansion, good dimensional stability, high elastic modulus, stable thermodynamic properties, and easy dispersion. It has a broad application prospect of wear-resistant ceramic-reinforced phase, and it has been widely used in the fields of wear resistance and high-temperature resistance and has been widely concerned by the material science circle [20-22]. TiC can be used as ideal second-phase reinforcement, often used as composite abrasives, as well as high-temperature oxidation and corrosion-resistant materials. TiC-containing composite materials are a hot field in the research of composite materials, and they have great application value and are constantly developing $[23,24]$. 
Compared with WC, TiC has a lighter weight and higher hardness. Emamian et al. have shown that TiC has a better effect than WC as a reinforcement and can obtain a higher wear resistance $[25,26]$. Currently, laser cladding of $\mathrm{Ni}$ based or Fe-based composite coatings using $\mathrm{TiC}$ as the ceramic reinforcement phase has been studied. $\mathrm{Wu}$ and Hong prepared two types of $\mathrm{TiC}_{\mathrm{p}} / \mathrm{Ni}$ alloy coatings on the surface of 5 CrMnMo steel: in situ $\mathrm{TiC}_{\mathrm{p}}$ coatings and directly added $\mathrm{TiC}_{\mathrm{p}}$ coatings. The study found that there is a pop-in phenomenon in the loading curve of the $\mathrm{TiC}_{\mathrm{p}}$ near interface. The interface hardness and elastic modulus of the substrate near the interface area are low. The loading curve of the in situ $\mathrm{TiC}_{\mathrm{p}}$ near the interface area does not have a pop-in phenomenon, and the hardness and elastic modulus are high and present a continuous gradient distribution characteristic. This presents that the in situ $\mathrm{TiC}_{\mathrm{p}}$ at the interface has high stiffness and strong toughness [27, 28]. Pei studied laser cladding $\mathrm{TiC}_{\mathrm{p}} / \mathrm{Ni}$-based composite wear-resistant coating on the surface of 45 steel. They have found that the rapid growth of $\mathrm{TiC}$ particles mainly comes from the collision and bonding of the particles. The solidification front preferentially captures the relatively slow floating TiC particles. The decisive factor leads to the in situ generation of the gradient structure of the cladding layer [29].

In order to obtain a high-quality coating, the ratio of the liquid phase to the ceramic phase in the coating should be controlled first. Gao et al. studied the $\mathrm{TiC} / \mathrm{Ni}$ laser cladding layer on the surface of titanium alloy. The results showed that $\mathrm{TiC}$ - and $\mathrm{Ni}$-based alloy powders were laser cladding at a ratio of $1: 3$ (vol.\%) to obtain a denser structure, with no pores and cracks. TiC/Ni-based coating hardness is 3 times that of the substrate, and the friction coefficient of the laser cladding layer increases with decreasing environmental pressure [30]. Xu et al. discussed the laser cladding of $\mathrm{TiC} /$ Fe-based composite coating on the surface of $0.2 \%$ carbon steel. The experimental results found that, with the increase in $\mathrm{TiC}$ content in the coating, the structural characteristics of $\mathrm{TiC} / \mathrm{Fe}$-based coating changed and the hardness increased. The thermal stress in the coating increases with the increase in the $\mathrm{TiC}$ content. When the content reaches 30\% (wt.\%), pores appear in the $\mathrm{TiC}$ aggregation, and the coating and the substrate have poor wetting and reverse warpage [31]. Pei et al. generated a $30 \% \mathrm{TiC}_{\mathrm{p}} / \mathrm{Ni}$-based composite wear-resistant coating on the surface of $0.45 \%$ carbon steel. They revealed that the coating structure is composed of $\mathrm{TiC}$ particles, $\gamma$-Ni solid solution dendritic primary crystals, and its interphase $\mathrm{M}_{23} \mathrm{C}_{7}+\gamma-\mathrm{Ni}$ eutectic composition; $\mathrm{TiC}$ particles are distributed in the $\gamma$-Ni crystal. The morphology of $\mathrm{TiC}_{\mathrm{p}}$ is closely related to its dissolution behavior during laser cladding. Its growth mechanism includes in situ precipitation, bridging growth, independent nucleation growth, and precipitate out [32]. Li et al. have successfully prepared an in situ $\mathrm{TiC} / \mathrm{Ni}$ composite coating on the surface of lowcarbon steel. They have found that the coating contains $\mathrm{TiC}$ particles and $\mathrm{Ni}$ phase, which shows that $\mathrm{TiC}$ particles are synthesized by the in situ reaction. In addition, with the increase in $\mathrm{TiC}$ content, the hardness and wear resistance of the composite coating increase [33]. However, too much TiC in the Co-based coating is not good for the bonding strength between the coating and the substrate because increasing the TiC content is decreasing the Co-based content. While Co plays the role of a bonding agent between the coating and the steel substrate, reducing it will lead to a decrease in the bonding quality. Therefore, increasing $\mathrm{TiC}$ too much or higher results in poor bonding coating, and they can be peeled.

The way of adding carbide ceramic reinforcing particles in the composite coating is divided into two types: external addition method and in situ self-generation method. Therefore, there are generally two ways to prepare metal-based ceramic composite coatings: adding ceramic reinforcement and in situ ceramic reinforcement. The most difficult problem is the interface problem between the external ceramic phase and the base metal: due to the large difference in thermal physical parameters between the external ceramic phase and the base metal, and there is an obvious interface, the particles are often oxidized and burned or melted and decomposed during the cladding process. It is easy to cause cracks in the coating and the loss of the reinforcing phase and the formation of the brittle phase in the coating, which greatly affects the application of this technology in actual production. In addition, the interface between the external ceramic phase particles and the metal matrix will form undesirable reactants and deposits, making the interface a weak interface with low strength and toughness. The reinforced particles are often susceptible to contamination during processing, which can easily lead to poor wettability of the particles and the matrix and low binding ability, thereby damaging the mechanical properties of the composite material. Many scholars have conducted a lot of research on this problem in order to solve or alleviate the cracking of the coating and have made great progress, but there has been no report on applying this technology to industrial production, and most are still in the laboratory research stage.

The carbide ceramic particle addition method is generally to precoat the reinforcement particles on the surface of the desired reinforcing substrate or mix it with the alloy powder to form the desired spray material. Laser and other heat sources are used to heat and melt the precoating or spraying powder so that the reinforcement particles enter the metal matrix to strengthen the substrate surface to form a metal matrix composite layer. The reinforcing particles are allowed to enter the surface of the metal matrix to strengthen the substrate and form a metal matrix composite layer. According to the temperature of the process, it can be divided into a liquid-phase process and a solid-phase process. Previous research reports on the method of adding particles are still rare, but because of the good effect of the added particles on the refinement and performance of the cladding layer, it has attracted more and more attention. A study by Huang et al. has shown that compared with in situ precipitation, the additive method is more controllable and overcomes the uncertainty and difficulty in the number and size of particles generated by the in situ precipitation method. The refinement of the original austenite grains and the later processing process both play a role [8].

In addition, the added particles are used as nucleation particles to provide a large number of dispersed particles to promote heterogeneous nucleation. During the solidification and rolling deformation of the molten steel, the 
structure of the steel material can be refined. You-Wei et al. studied the influence of chemical composition on the structure and properties of $\mathrm{TiC}_{\mathrm{p}} / \mathrm{Fe}$ in situ composites and pointed out that $\mathrm{C}$ is a key factor affecting the growth of crystal nuclei [9]. However, when the composition ratio of $\mathrm{C}$ and $\mathrm{Ti}$ is significantly higher than the standard stoichiometry of $\mathrm{TiC}$, harmful flake graphite will be produced in the structure, thereby reducing the impact toughness and hardness of the material. From the above research results, it can be seen that the addition of ultrafine particles to the steel has a very good effect on the refinement of the structure and performance improvement of the steel. The laser cladding and ceramic particle-reinforced metal matrix composite coating technology are simple and easy to implement, but this method still has many problems in the modern metallurgical production process.

The method of the mechanical application of ceramic particles is generally to directly add the ceramic phase to the laser melting pool, or the ceramic phase is first made into a mechanically mixed powder or coated powder with the metal powder and then laser cladding. The coated powder is most widely used in Co-coated WC and Ni-coated WC. During laser cladding, the core material is protected by the coating material, which can reduce or prevent the burning of the core material and improve the coating performance. The coated powder is significantly different from the mechanically mixed powder made from powders with different components. The single particles in the powder are composed of two or more solid-phase materials with different compositions and have obvious phase interfaces, and the mechanical components between the phase components are generally mechanical. These aspects will lead to coating cracking or peeling damage during the application process $[12,13]$ and will also bring some difficulty in the cladding process, and the particle phase size is determined by the size of the added ceramic particles. It is generally several tens of micrometers, rarely less than $1 \mu \mathrm{m}$, and the distribution of particles is difficult to control. Furthermore, the external ceramic phase and the alloy easily interact with each other at high temperatures, resulting in the burning of the ceramic phase.

This paper focuses on the wear resistance and hardness of Co-based alloy coatings and TiC/Co-based composite coatings at both room and high-temperature conditions. The effects of different $\mathrm{TiC}$ contents, loads, rotation speeds, and temperatures on the dry sliding friction and wear properties of $\mathrm{TiC}$ particle-reinforced Co-based coatings were studied. Through analysis of wear morphology, microstructure, and high-temperature dry friction and wear properties, the mechanism of high-temperature friction and wear was discussed to provide a reference for the practical applications.

\section{Experimental Method}

2.1. Materials and Experimental Methods. The experiment selected H13 steel, with some main components shown in Table 1 . The steel sample size is $100 \mathrm{~mm} \times 30 \mathrm{~mm} \times 10 \mathrm{~mm}$. The chemical compositions of self-melting Co50 alloy powders are listed in Table 2. The Co50 particle size is about
TABLE 1: Chemical composition of the H13 steel sample using in the experiment (weight).

\begin{tabular}{lccccccr}
\hline Element & $\mathrm{C}$ & $\mathrm{Si}$ & $\mathrm{Mn}$ & $\mathrm{Cr}$ & $\mathrm{Mo}$ & $\mathrm{V}$ & $\mathrm{Fe}$ \\
\hline$\%$ & 0.43 & 1.17 & 0.48 & 4.79 & 1.38 & 0.94 & Bal. \\
\hline
\end{tabular}

TABle 2: Chemical composition of Co powder using in the experiment (weight).

\begin{tabular}{lccccccccc}
\hline Element & $\mathrm{C}$ & $\mathrm{W}$ & $\mathrm{Si}$ & $\mathrm{B}$ & $\mathrm{Cr}$ & $\mathrm{Mo}$ & $\mathrm{Fe}$ & $\mathrm{Co}$ & $\mathrm{Ni}$ \\
\hline$\%$ & 0.6 & 3.0 & 3.5 & 2.25 & 20.0 & 5.1 & 5.0 & Bal. & 14.0 \\
\hline
\end{tabular}

$53 \mu \mathrm{m}$. TiC powder has $99.5 \%$ purity, and its particle size is around $10 \mu \mathrm{m}$. Initially, the steel surface is cleaned up by abrasive paper, rinsed with alcohol and acetone liquid, and then dried by oven. Then, a preplaced powder layer that used a homemade binder coats the test sample. After that, an LC method is applied to melt it. Preplaced powder layers consist of a Co50 alloy powder layer and 10\%, 20\%, and 30\% $\mathrm{TiC}+\mathrm{Co} 50$ composite powder layer ( $\%$ by weight), with $\sim 1 \mathrm{~mm}$ thickness. Those preplaced powder layers on H13 steel surface are then dried in an oven for 8 hours, before being melted down by the LC method.

Laser cladding Co50 coating and Co50/TiC composite coating are made at Kunming University of Science and Technology. LC machine is the type of GS-6000 TFL transverse-flow $\mathrm{CO}_{2}$ with the main parameters: the laser power $3.3-4.2 \mathrm{~kW}$, scanning speed $350-500 \mathrm{~mm} / \mathrm{min}$, the distance from the laser head to the based steel surface $50 \mathrm{~mm}$, and flow of Argon air protective coating $8 \mathrm{~L} / \mathrm{h}$; the remaining technology parameters are given in Table 3.

2.2. Methods for Determining the Mechanical Properties. The experiment chose a hardness testing machine type HMV-WIN, with load $1.961 \mathrm{~N}\left(\mathrm{HV}_{0.2}\right)$, and stopped time is $15 \mathrm{~s}$ to test. A bonding zone is selected between the coating and H13 steel as the origin, and then, the samples are measured hardness above and below the origin, in which the top origin is a positive value and vice versa. Wear-by-friction testing machine is used at high-temperature-type MMU-5G to study the wear resistance of coatings from room temperature to high-temperature with pin-on-disc wear of friction pairs (Figure 1(a)). This type of equipment is often selected to test a laser coating. Some main technical indicators of the testing machine are listed as follows; for instance, test force: the working range of the axial test force is $10-5000 \mathrm{~N}$.

The error range of testing force is $\pm 1 \%$; therefore, the error range of the $\mathrm{CoF}$ which is the ratio between the friction force and the normal force is $\pm 2 \%$. Friction torque: the maximum friction torque is $5 \mathrm{~N} \cdot \mathrm{m}$; the relative error of the friction torque indication is $\pm 2 \%$. Spindle speed-changing system: single-stage transmission system $0.1-2000 \mathrm{r} / \mathrm{min}$; spindle speed error $\pm 1 \%$. Temperature: the temperature of the cylindrical heating furnace is $\sim 1100^{\circ} \mathrm{C}$; 2 K-type thermocouples (with a cylindrical heating furnace); temperature control accuracy $= \pm(0.3+0.005 t)\left({ }^{\circ} \mathrm{C}\right)$, in which " $t$ " is the absolute value of the test temperature. 
TABLE 3: Technical parameters and samples surface of the LC method applied in the experiment.

\begin{tabular}{lccccc}
\hline Sample & Co50 (wt.\%) & TiC (wt.\%) & Laser power $P(\mathrm{~kW})$ & Scanning speed $V_{s}(\mathrm{~mm} / \mathrm{min})$ & Laser power density $P_{w}\left(\mathrm{~kW} \cdot \mathrm{s} / \mathrm{cm}^{2}\right)$ \\
\hline S0 & 100 & 0 & 3.3 & 400 & 12.57 \\
S1 & 90 & 10 & 3.6 & 500 & 10.97 \\
S2 & 80 & 20 & 3.9 & 350 & 16.98 \\
S3 & 70 & 30 & 4.2 & 350 & 18.29 \\
\hline
\end{tabular}

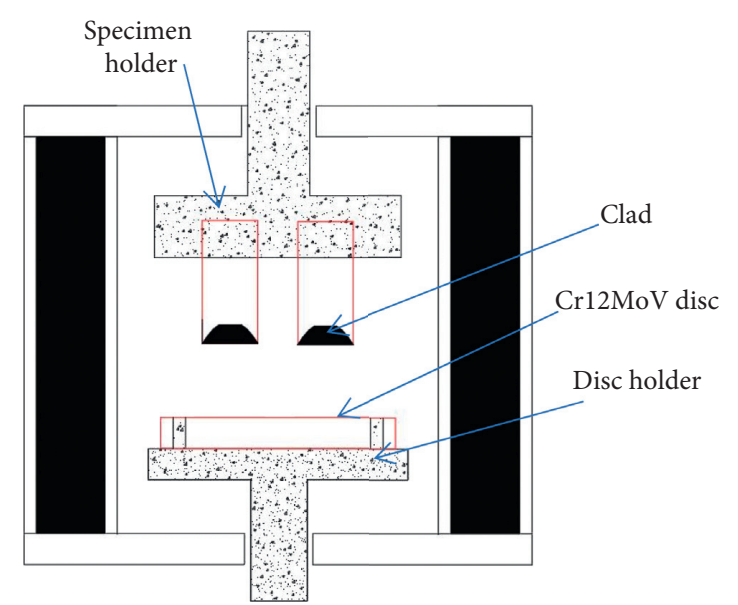

(a)
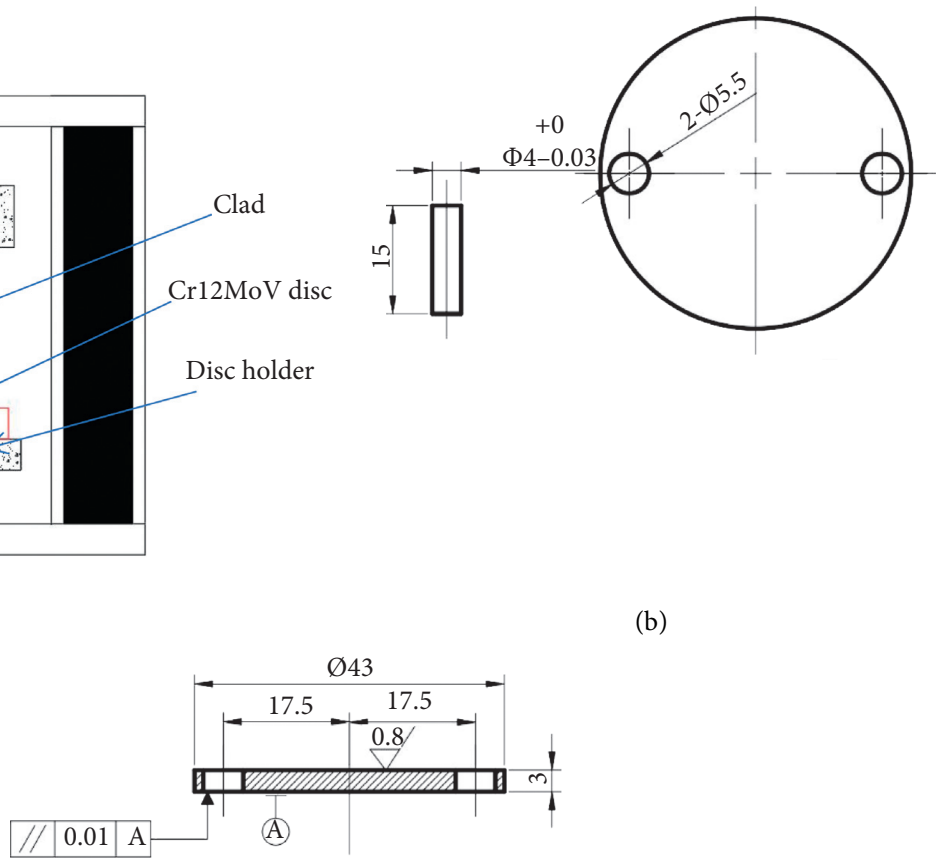

(b)

(c)

FIGURE 1: Pin-on-disc wear of friction pairs and friction testing samples: (a) MMU-5G high-temperature wear tester and its principle; (b) upper specimen; (c) friction pair.

In this test, the force experiment value is chosen as $98 \mathrm{~N}$, the speed is $200 \mathrm{r} / \mathrm{min}$, wear time is $2 \mathrm{~h}$, and run out $3 \mathrm{~min}$. The upper sample employed H13 steel, Co-based coating, and $\mathrm{TiC} / \mathrm{Co}$-based composite coating with $\varphi 4 \times 15 \mathrm{~mm}$ of size and 3 samples/one time experiments (Figure 1(b)). The lower sample (friction pair) uses $\mathrm{Cr} 12 \mathrm{MoV}$, which is cold work tool steel heat-treating (Figure 1(c)).

The friction coefficient is applied as the index of friction and wear performance, and its value is read directly by the testing machine. The upper sample uses the amount of wear as the wear performance index. Relative wear resistance expresses the comparison of the wear resistance of $\mathrm{H} 13$ steel, Co-based coating, and TiC/Co T-based composite coating. The calculation of the amount of wear can be calculated according to following equation:

$$
\Delta L=\frac{M_{1}-M_{2}}{T S \rho}
$$

where $\Delta L$ is the wear rate of the sample, $M_{1}$ is the weight before testing the sample, $M_{2}$ is the weight after testing, $T$ is the wear time, $S$ is the wear surface area, and $\rho$ is the density of the sample.
The accuracy of the wear rate mainly depends on the accuracy of the accuracy of measuring $M_{1}$ and $M_{2}$ and normal pressure $P$. Since the accuracy of normal pressure is $\pm 1 \%$, the accuracy of the microbalance is $0.1 \mathrm{mg}$, which is very small compared to the weight of the sample. Therefore, the accuracy of the wear rate is $\pm 2 \%$.

The CoF can be read directly by the tester. By measuring the normal force and frictional force, the machine can calculate the CoF. The normal force is a certain force and is set up with $98 \mathrm{~N}$. Figure 2 shows the interface of MMU-5G machine testing system. Testing parameters such as test force, sliding speed and temperature can be set directly and recorded in real-time. The friction force and friction coefficient can be saved directly as dynamic curves on the computer. In testing machine type MMU-5G, the friction force was continuously measured using a strain gauge $[34,35]$.

2.3. Data Collection and Analysis System. Figure 2 shows the interface of MMU-5G machine testing system. Testing parameters such as test force, sliding speed, and temperature can be set directly and recorded in real time. The friction 


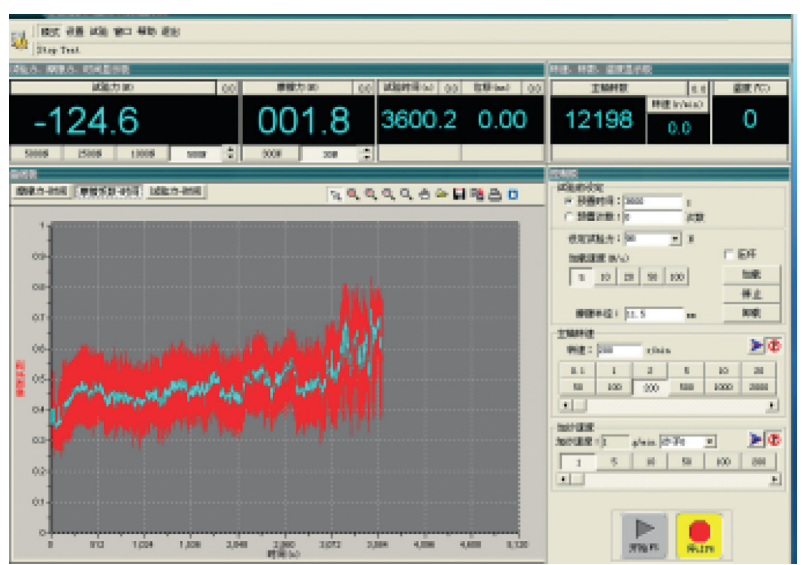

FIGURE 2: Screen-display of friction and wear machine testing system.

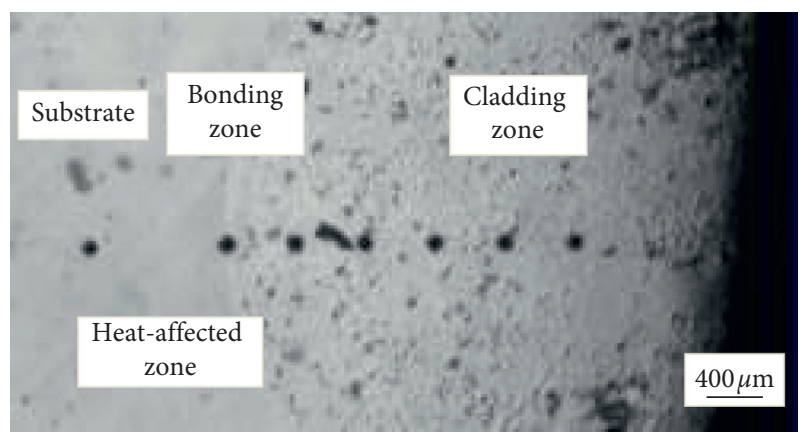

FIgURE 3: Appearances of hardness marks.

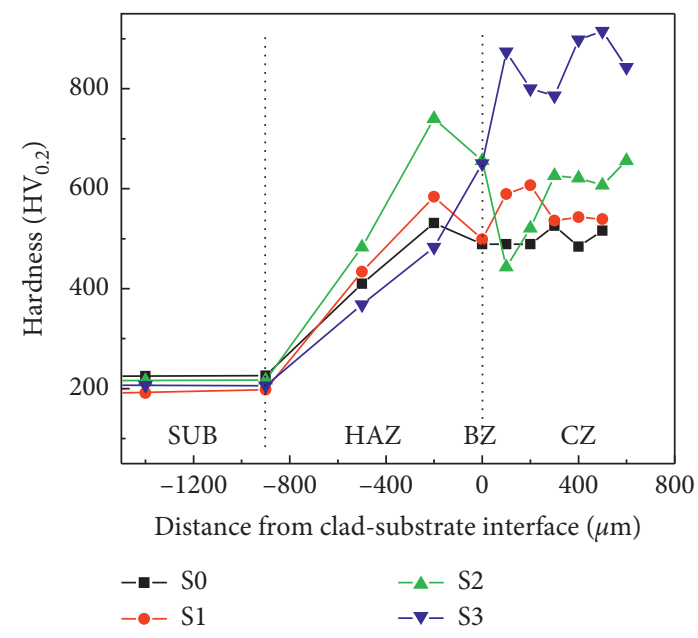

FIGURE 4: Cross section microhardness distribution of the laser cladding.

force and friction coefficient can be saved directly as dynamic curves on the computer.

\section{Results and Discussion}

3.1. Analysis of Microhardness. Figure 3 shows the appearances of hardness marks, and Figure 4 illustrates the microhardness distribution of the coatings. The hardness of the coatings is classified into three distinct areas, and the hardness variation in these areas is quite high. The average hardness number of $\mathrm{H} 13$ steel is $208 \mathrm{HV}_{0.2}$, while the average hardness numbers of S0, S1, S2, and S3 coatings are 499 $\mathrm{HV}_{0.2}, 552 \mathrm{HV}_{0.2}, 590 \mathrm{HV}_{0.2}$, and $824 \mathrm{HV}_{0.2}$, respectively. The hardness values of all S0, S1, S2, and S3 coatings are higher than $\mathrm{H} 13$ steel 2.4, 2.7, 2.8, and 4.0 times, respectively. From the steel substrate to the top of the coating, the hardness increases rapidly, which means the abrasive resistance of the workpiece also increases accordingly. These results prove that, after applying the LC method, the hardness of the $\mathrm{H} 13$ steel surface is significantly improved. The BZ between the coating and the steel substrate has a lower hardness than the $\mathrm{CZ}$. Because the Fe atoms from the substrate diffuse into the coating during the melting process, these $\mathrm{Fe}$ atoms have a bad effect of diluting other components, leading to a decrease in the hardness of the BZ. The HAZ has a higher hardness than the substrate. The main reason is that Co and Mo elements and other alloy elements, under the heat effect of laser beams, diffuse into the steel substrate, forming a stronger solid solution [10]. In addition, due to the heat effect of the laser beam, the temperature of the HAZ is higher than the critical point $\mathrm{A}_{\mathrm{C} 3}$, and then, the temperature drops suddenly. This is considered as HAZ is quenched, similar to a martensite transformation when rapidly cooled from austenite, making the hardness of this area is relatively high. Far away from BZ, this quenching effect is weaker due to the smaller temperature difference between heated and nonheated areas; therefore, the hardness number decreases gradually [11].

The laser cladded region consists of $\gamma$-Co, $\mathrm{TiC}, \mathrm{Co}_{3} \mathrm{Ti}$, and $\mathrm{CoO}$ phases, as shown in XRD results. As the hardness of these phases varies in a wide range, TiC possesses a very high hardness and $\gamma$-Co has a much lower hardness. These phases do not evenly distribute in the laser cladded region, as shown in Table 4. Moreover, as the HV microhardness tester has a very small indenter, the hardness number presents a localized value. Therefore, the hardness of the cladded region presents a variation.

The hardness of the S0 coating is improved because of the appearance of a high hardness $\mathrm{Cr}_{1.12} \mathrm{Ni}_{2.88}$ phase. This phase is well dispersed on the matrix of $\gamma$-Co solid solution, forming a eutectic microstructure with a high hardness, which hinders the development of the grain, thereby producing a microstructure of fine grains. Moreover, the alloy Co50 consists of $\mathrm{Cr}, \mathrm{Ni}, \mathrm{Fe}$, and $\mathrm{C}$ elements, so during the scanning process of the laser beam, these elements dissolve into a solid solution of $\gamma$-Co, which strengthens the solid solution.

S1, S2, and S3 coatings have a higher hardness than S0. As increasing $\mathrm{TiC}$ content, the hardness of the coatings increases. The main reason is that $\mathrm{TiC}$ which has extremely high hardness is increased, and the newly formed phases have higher hardness and melting points. Additionally, the $\mathrm{Ti}$ and $\mathrm{C}$ atoms themselves react to form a new $\mathrm{TiC}$ with a better structure than before. In addition, the coatings also have nonmelting TiCs and partially melting $\mathrm{TiC}$ that retains 

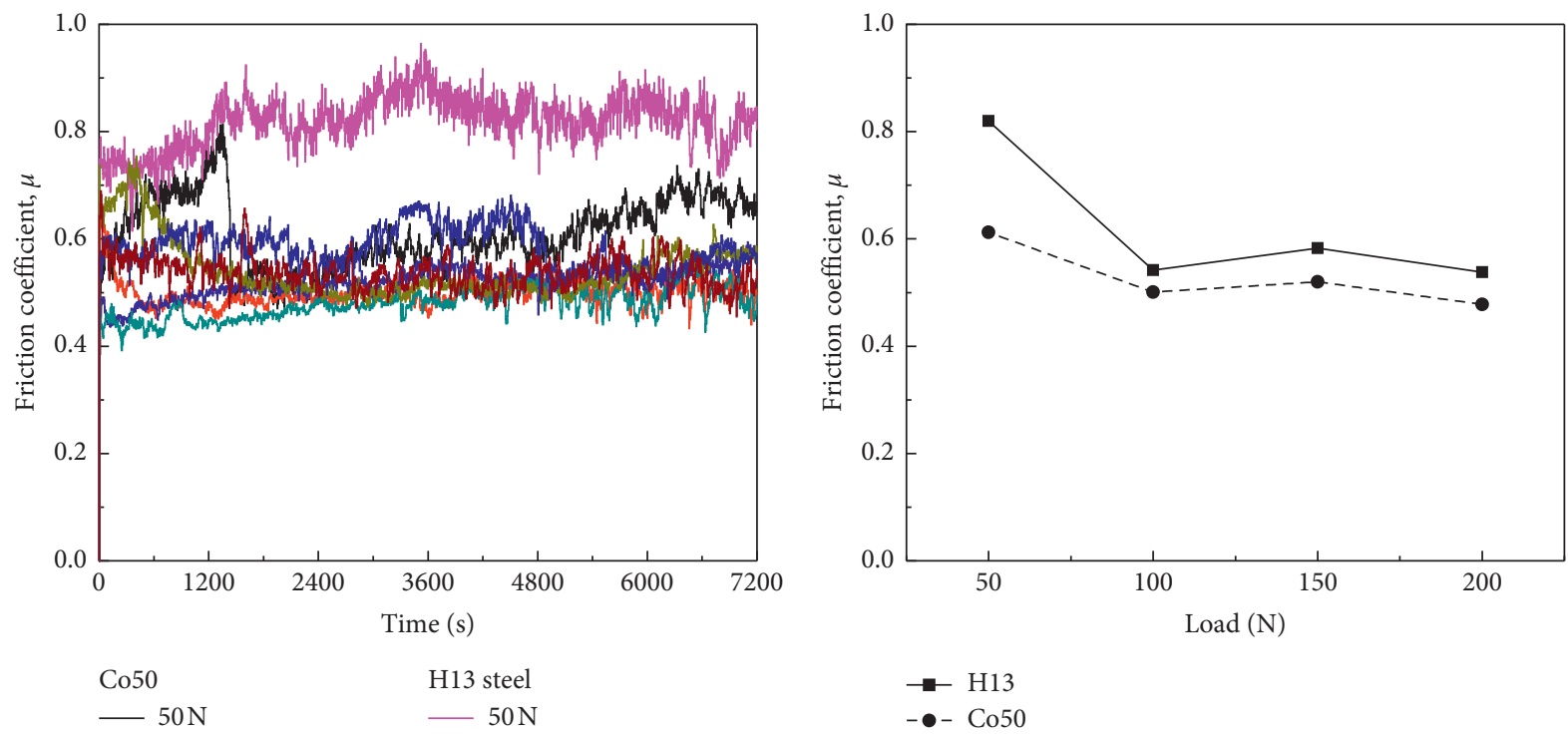

$\begin{array}{ll}\text { Co50 } & \text { H13 steel } \\ -50 \mathrm{~N} & -50 \mathrm{~N} \\ -100 \mathrm{~N} & -100 \mathrm{~N} \\ -150 \mathrm{~N} & -150 \mathrm{~N} \\ -200 \mathrm{~N} & -200 \mathrm{~N}\end{array}$

(a)

(b)

Figure 5: Effect of the load on the friction coefficient at the speed of $200 \mathrm{r} / \mathrm{min}$ : (a) friction coefficient of S0 coating and H13 steel; (b) the average friction coefficient.

TABLE 4: Microstructure with different shapes of TiC.

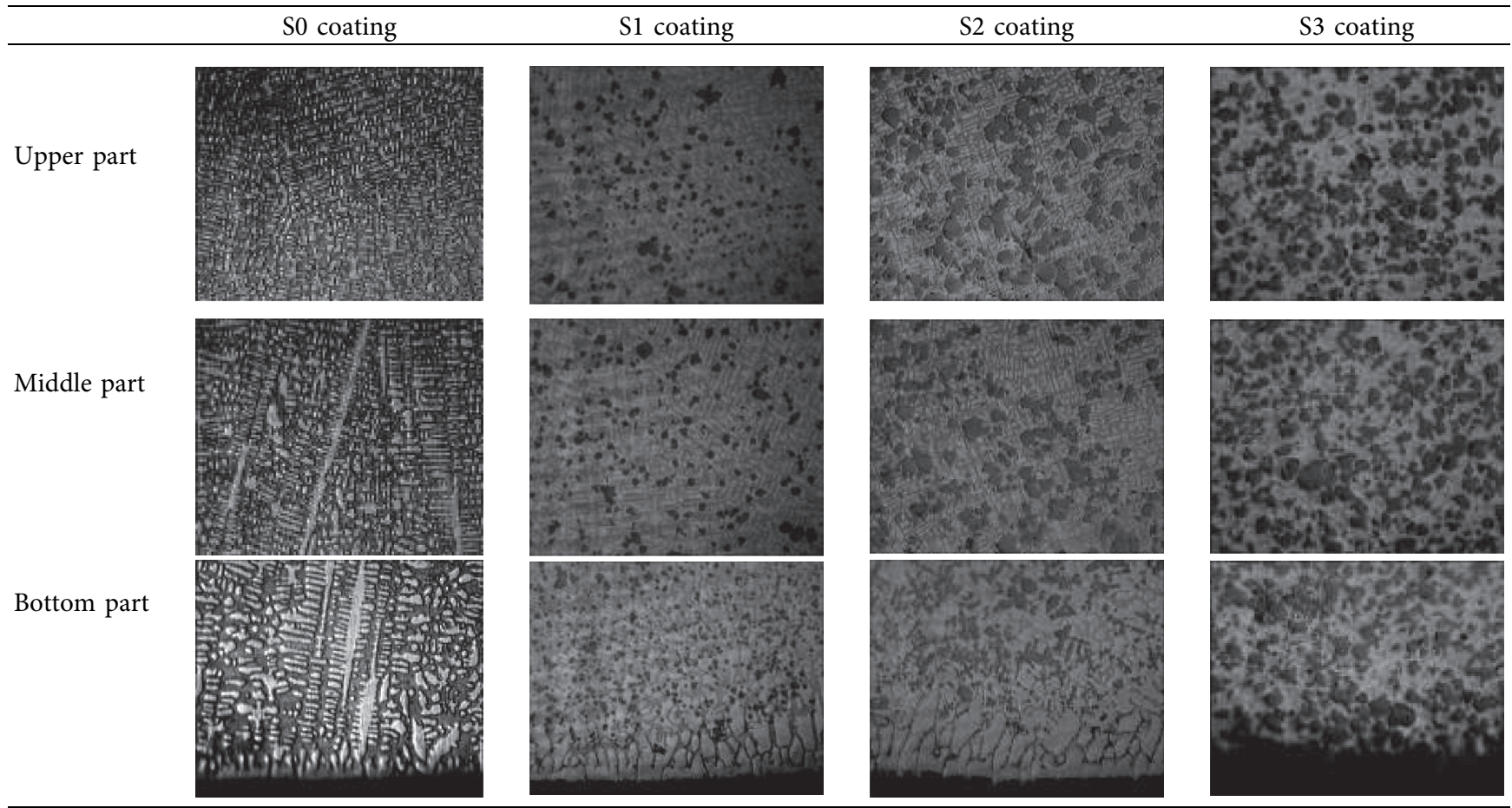

the main characteristics of carbides. They are fine particles and dispersed uniformly, improving the strength and the hardness of this coating [2].

The hardness changes and uneven distribution of S1, S2, and S3 coatings appear due to the existence of a large number of incompletely dissolved $\mathrm{TiC}$ particles and in situ TiC. During the LC process, the original TiC particles were burnt, contaminated by the interface, and the melting phase of the enhanced phase was deficient. The TiC particles in situ were generated by an in situ reaction, thus solving the 
problems of enhanced phase thermal stability and interface. When testing the hardness, the hardness value of in situ TiC particles is higher than that of other regions, which is the main reason for the uneven distribution of microhardness of the coating.

\subsection{Analysis of Overlay Shape with Different Component} Ratios and Different Technology Parameters. The specific laser power density corresponding to each coating is shown in Table 3. The laser power density is determined by the laser power and the size of a laser pointer. Typically, the higher the laser power, the easier it is to perform the spraying, but it is difficult to clad due to conditions and costs of the equipment. In contrast, for small laser power, maximum nozzle wattage is limited, and the energy density of the laser scanning process becomes the most important parameter that affects the performance of the coating. During the crystalline coating process, laser power density and scanning speed will determine the temperature and heating time of laser energy for the precoating powder. Generally, when the laser power is small and the scanning speed is high, the coating will have a low firing temperature, short duration, and small coating thickness. By contrast, when the laser power density is high and the scanning speed is low, the coating will evaporate and the thickness of the coating is also reduced. But when the thickness of the coating increases, its dilution rate decreases rapidly, and the occurrence of defects such as pitting, cracking, and peeling in the coating also increases. With the appropriate combination of laser power and scanning speed, the thickness and the quality of the coating can be optimized.

The existence of the coating compounds morphology and macrograph of the coating from the transverse cross section with different component ratios is shown in Table 5. Overall, as the ratio of $\mathrm{TiC}$ in the coating increases, the appearance of the coating changes from bright white to black color. S0 coating has a distinctive bright white color and a relatively smooth surface, and the two side edges are also quite smooth. On two edges of S1 coating, there are some residual spraying materials. Moreover, on the surface of the coating, there are a lot of porous materials. In contrast, S2 has better quality than S1, but the coatings have a large undulating level, and the flatness of the coatings is quite low. In addition, there is still residual spraying material, and the surface of the coatings still has porous. Lastly, the S3 sample has a good surface morphology, and there is no porosity on the surface, but cracks appear in the surface which is almost perpendicular to the scanning direction of the laser beam. Moreover, S3 coating also has a small undulating and peeling phenomenon.

3.3. Analyzing Microstructure. Table 4 shows the microstructures of the four coating sections. It can be seen that a very narrow "white bright band" appears at the interface between the S0, S1, and S2 coatings and the substrate, which shows that a good metallurgical bond is formed between the
S0, S1, and S2 coatings and the substrate and the S3 coating. Because the TiC content is relatively large, the coating cannot be combined with the substrate. The structure characteristics of the S0 coating have obvious white dendrites and gray eutectic structure between the dendrites. Among them, the morphology of the dendrites is a little complicated: the bottom of the coating has the growth characteristics of columnar dendrites and is perpendicular to the bonding area. It develops towards the solidification of the coating surface and the middle of the coating transitions from a large number of columnar dendrites to dendrites; the surface layer of the coating is mainly equiaxed. It can be found that the size of the dendrite and eutectic is related to the relative position in the coating. The farther the away from the bonding zone, the finer the dendrite, and the smaller the eutectic structure spacing. A comparative study shows that the microstructure of S1, S2, and S3 coatings has more black TiC particles than S0 coatings, and the TiC particles are dispersed and can play a good role in hard reinforcement. In addition, compared with the S0 coating, the S1, S2, and S3 coatings have no neat columnar dendrite composition and no obvious dendrite growth direction, and only a small amount of dendrites and more eutectic structures exist. In addition, as the amount of $\mathrm{TiC}$ in the precoat increases, the $\mathrm{TiC}$ content of the coating increases accordingly.

In addition, Table 4 also shows the microstructure with different shapes of TiC on S1, S2, and S3 coatings. It can be seen that, in the $\mathrm{S} 1$ coating, besides the original $\mathrm{TiC}$ particles (black) that are not fully melted, there are also primary TiC particles (white) that are precipitated in situ from the liquid phase during solidification. Observing the morphology of $\mathrm{TiC}$, it can be found that, from the bottom to the surface layer, the morphology of incompletely melted $\mathrm{TiC}$ is mainly spherical, while $\mathrm{TiC}$ precipitated in situ exists in different forms. The morphology of $\mathrm{TiC}$ in the $\mathrm{S} 1$ coating structure is different due to its different parts in the molten pool; its composition, temperature distribution, and cooling rate are different. TiC in the middle and the surface of the coating is a large block structure, while the bottom of the coating has a low temperature and insufficient melting, the rapid heat transfer effect of the cold matrix and the cooling rate are large, and the $\mathrm{TiC}$ grains are too late. It has stopped growing when it is large, so a fine granular structure is formed. S2 coating indicates a large amount of $\mathrm{TiC}$ in the form of cross petals and twigs. In the middle part and upper part, TiC mostly exists in a spherical shape. TiC behaves in two ways in the alloy melt: one is that $\mathrm{TiC}$ has been completely dissolved and presents a large, densely distributed and developed dendritic morphology. Moreover, the developed dendrites are mostly cross-shaped, and the orientation tends to be consistent; the second is that the $\mathrm{TiC}$ particles in the added powder are not completely dissolved and mainly exist as spherical structures. Especially, in the coatings, the size of $\mathrm{TiC}$ varies greatly: from the bonding zone to the surface of the coating, the size of TiC gradually increases. In the S3 sample coating, the figure points out that $\mathrm{TiC}$ exists like a 


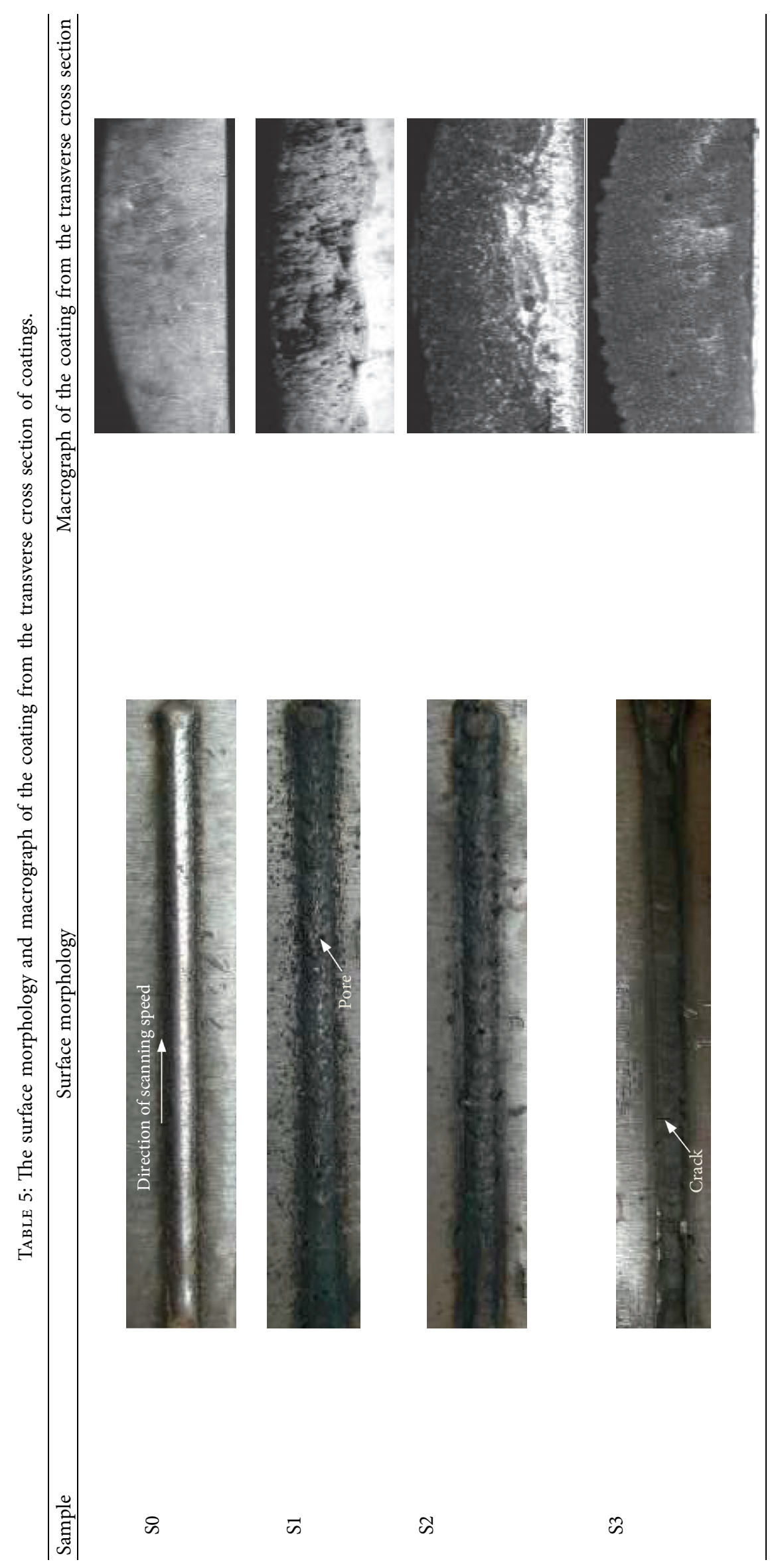




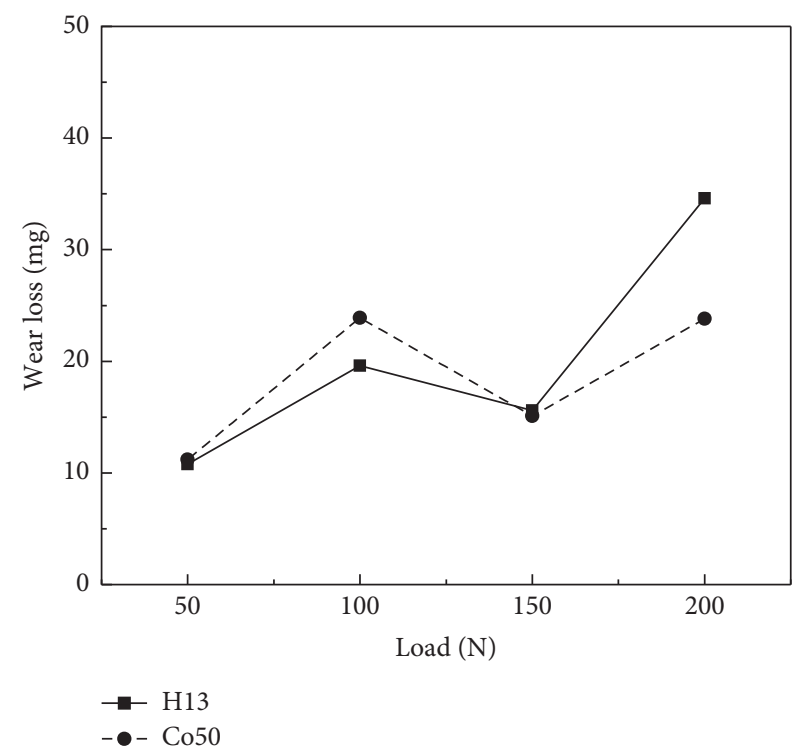

(a)

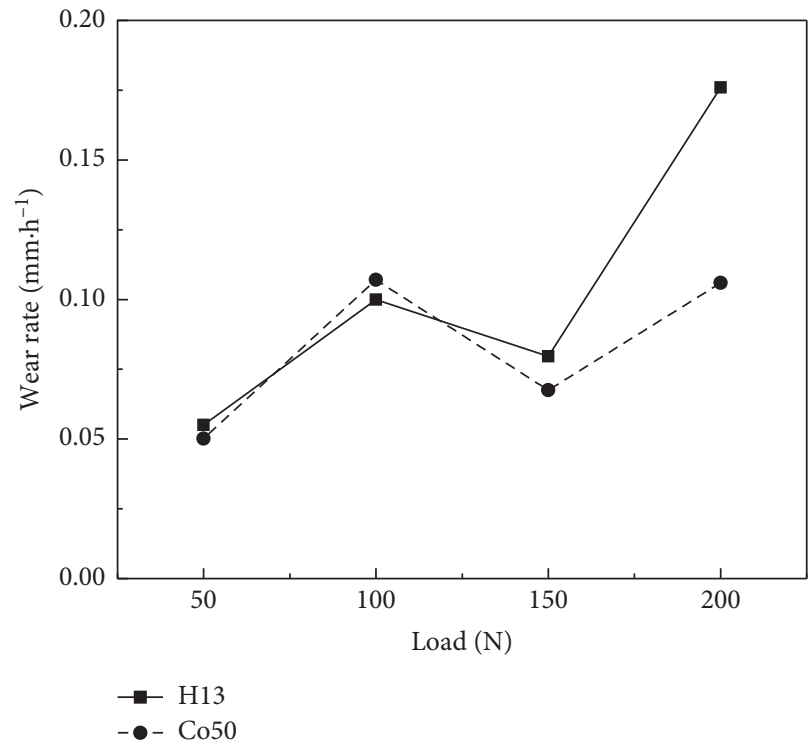

(b)

Figure 6: Effect of load on the (a) wear weight losses and (b) wear rates.

large number of diffusely distributed spherical structures. Unlike S2 coating, TiC particle size in S3 coating has no clear gradient change.

3.4. Effect of Load on Friction and Wear Properties of H13 and Co50 Coatings. Figure 5 shows the effect of the load on the wear coefficient at a speed of $200 \mathrm{r} \cdot \mathrm{min}^{-1}$. The friction coefficient of H13 steel and S0 coating decreases with the increase in the load, reaching the largest value at a load of $50 \mathrm{~N}$. As the load increases, the microconvex body of the contact surface is deformed, and the contact area of the friction pair and the friction force increases. According to adhesion theory, when the stress is not large, the contact between the two surfaces exists in an elastic state. At this time, the real contact area is proportional to the $2 / 3$ power of the pressure, and the friction force is proportional to the real contact area and, therefore, inversely proportional to the $1 / 3$ of the stress. According to the classic tribological formula, the friction coefficient is the ratio of the friction force to the normal force. Hence, if other conditions remain unchanged, as the load increases, the coefficient of friction decreases. At this time, since the contact area of the friction pair no longer increases significantly, the magnitude of increase in the friction force is not as large as that of the load, so the friction coefficient decreases as increasing stress.

When the load is less than $100 \mathrm{~N}$, the friction coefficients of the two materials are more different than that of more than $100 \mathrm{~N}$, and the friction coefficient of $\mathrm{H} 13$ steel is higher than S0 coating. When a load of H13 steel and S0 coating is $100 \mathrm{~N}$, the friction coefficient is relatively stable, as shown in Figure 5(a). As the load increases from $100 \mathrm{~N}$ to $200 \mathrm{~N}$, the friction coefficient fluctuates slightly. As the stress increases to a certain degree, the particles are stuck off or embedded in the friction parts, which make the actual contact area increase accordingly. Therefore, the friction coefficient does not change much. The high hardness phases in S0 can make the actual contact area smaller than in $\mathrm{H} 13$ steel, so the friction coefficient of S0 is lower than $\mathrm{H} 13$ steel.

Figure 6 shows the relationship between the amount of wear weight loss and the wear rate as a function of load. It can be seen that when the loads of H13 steel and S0 coating increase from $50 \mathrm{~N}$ to $100 \mathrm{~N}$, the wear rate increases. However, at $150 \mathrm{~N}$, the wear rate decreases. For further improvement in the load, the wear rate rises again. When the load is $200 \mathrm{~N}$, the wear rate reaches the maximum value. In general, the wear rates of $\mathrm{H} 13$ steel and S0 coating both mostly increase with the increase in the load. Generally, the wear rate increases gradually on increasing the load. Due to the increased load, the temperature rises and the material is softened. As a result, the friction coefficient and the wear rate will be reduced. The data show that, under different loads, the S0 coating has better wear resistance than H13 steel, especially at $150 \mathrm{~N}$ and $200 \mathrm{~N}$. The larger the load is, the more wear-resistant the $\mathrm{S} 0$ coating than $\mathrm{H} 13$ steel is, which can greatly improve the serving life of the coated parts.

\subsection{Effect of Sliding Speed on Wear-Resistant H13 and Co50} Coatings. Figure 7 shows the effect of sliding speed on the friction coefficient. As the sliding speed increases, the friction coefficients of $\mathrm{H} 13$ steel and S0 coating show a trend of decreasing first and then increasing. Heat and temperature changes due to the sliding speed will change the properties of the surface layer and the interaction. As damage conditions during the friction process alter, the friction coefficient also changes. When the sliding speed increases, the atoms on the surface of the friction pair, which are in an unbalanced state, interacts with the surrounding media to produce a surface film. 

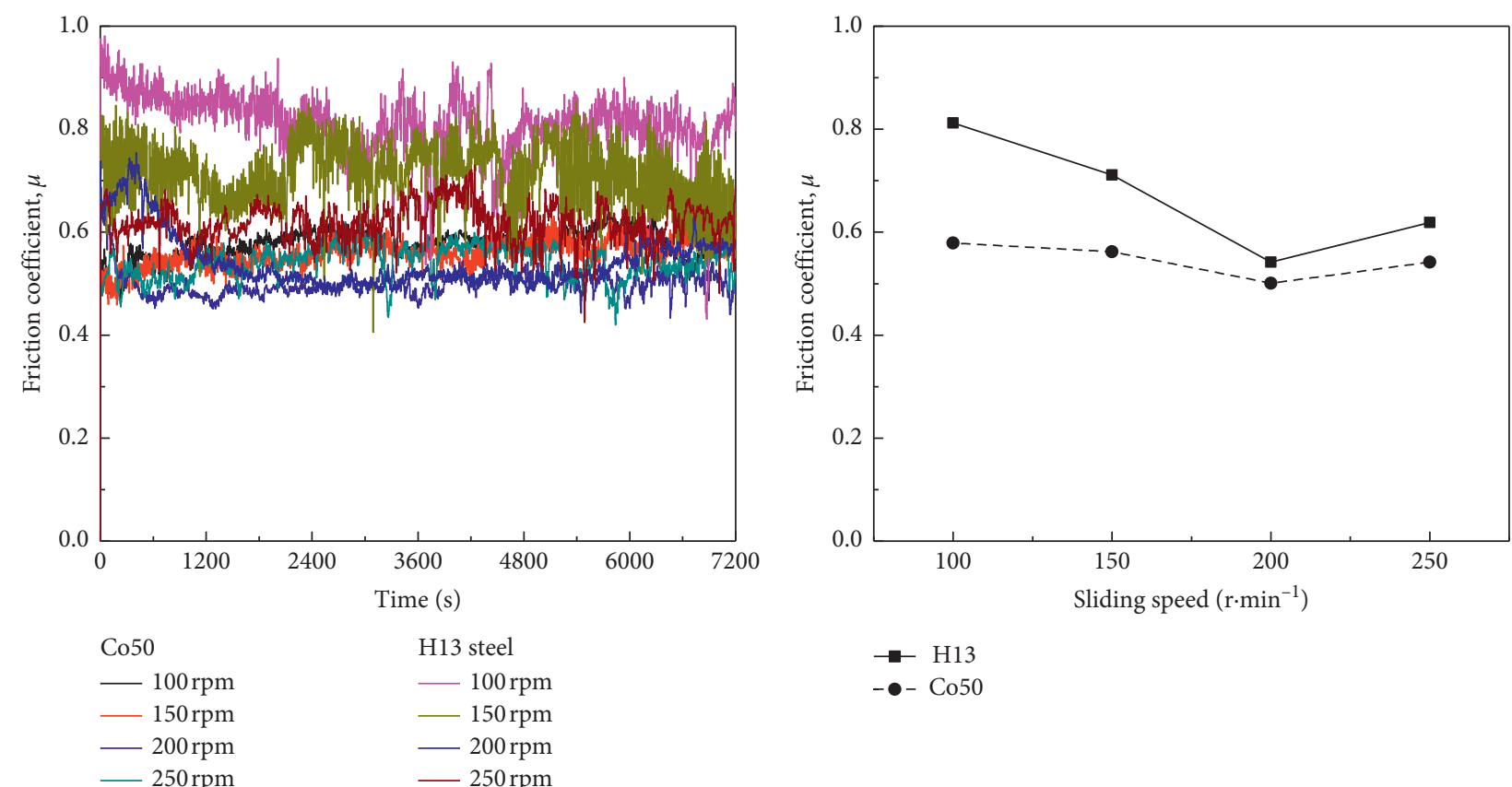

(a)

(b)

FIGURE 7: Effect of sliding velocity on the friction coefficient at the load of $100 \mathrm{~N}$ : (a) S0 coating and H13 steel; (b) the average friction coefficient.

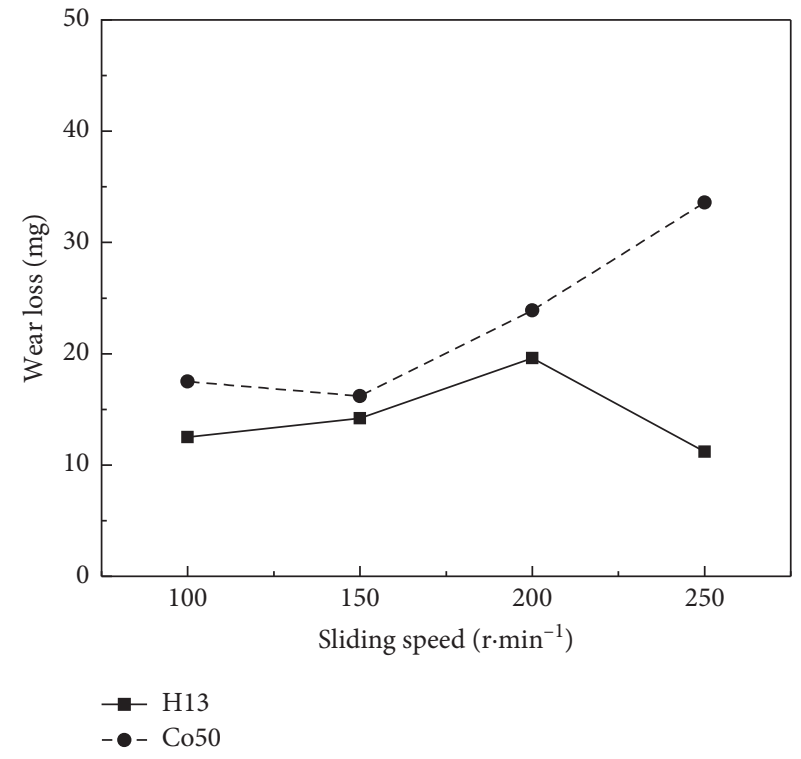

(a)

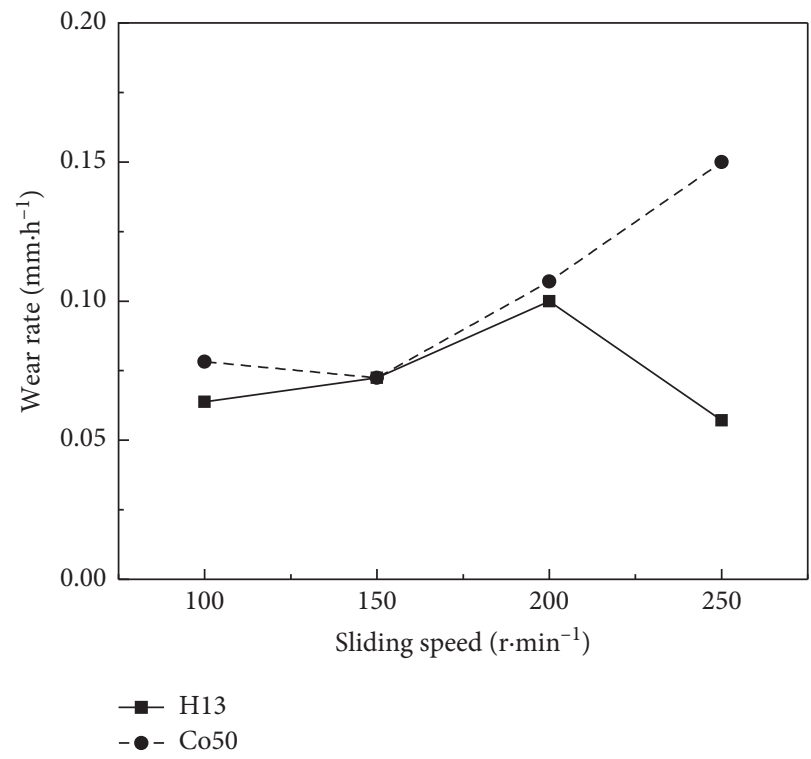

(b)

FIGURE 8: Effect of sliding velocity on (a) wear losses and (b) wear rates.

The surface deformation and temperature rise during friction lead to promoting the formation of the surface film. Due to the existence of the surface film, the atomic or ionic bonding force between the friction pairs is replaced by the weaker Van der Waals force. The impact of reducing surface molecular forces reduces the effect of surface molecular forces. In addition, as the mechanical strength of the surface film is lower than that of the base material, shear resistance decreases, and the friction coefficient also decreases. As the sliding speed enhances, the surface film is strongly destroyed, the surface roughness and the wear debris increase, and the friction coefficient also rises.

Figure 8 shows the effect of sliding speed on the amount of wear and the wear rate of $\mathrm{H} 13$ steel and S0 sample. With H13 steel, when the sliding speed of H13 steel is less than $200 \mathrm{r} / \mathrm{min}$, the wear rate increases, as shown in Figure 8(a). 


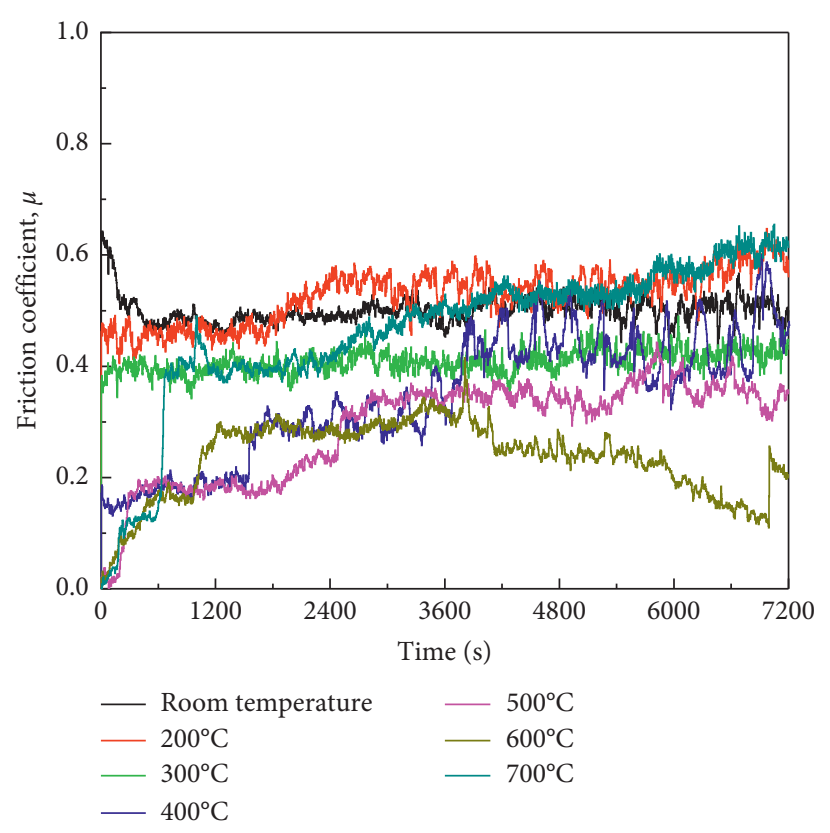

(a)

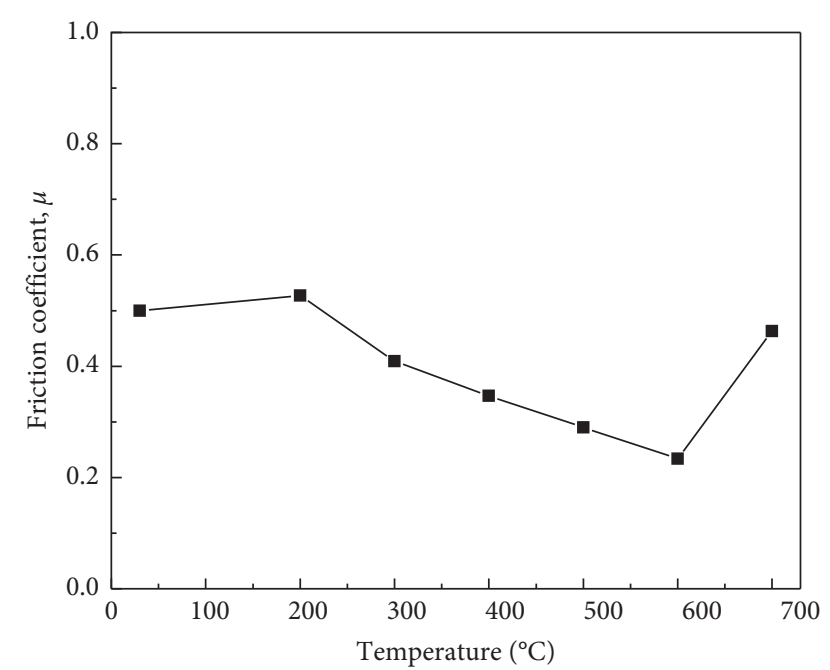

(b)

Figure 9: Friction coefficients of S0 coating: (a) From room temperature to $700^{\circ} \mathrm{c}$ and (b) the average friction coefficient

When the sliding speed exceeds $200 \mathrm{r} / \mathrm{min}$, the wear rate decreases. With the S0 sample, the wear rate mostly increases as increasing the sliding speed. When the sliding speed improves from 100 to $150 \mathrm{r} / \mathrm{min}$, the wear rate decreases slightly. Above the speed of $150 \mathrm{r} / \mathrm{min}$, the wear rate of the $\mathrm{S} 0$ coating increases rapidly as increasing the sliding speed.

When the sliding speed is less than $150 \mathrm{r} / \mathrm{min}$, the temperature of the surface of the friction pair is not high, and the friction surfaces are not softened. In addition, the surface film will be generated to maintain the friction surface. At lower sliding speeds, the shear and furrow forces are smaller; therefore, the wear rate is lower, as shown in Figure 8(b). As the sliding speed increases, the temperature of the friction surface increases, and a severe oxidation process will occur. The oxide film will rupture at a large sliding speed. At the same time, the increase in temperature will weaken the material's resistance to plastic deformation and cause serious wear. The wear rate has increased significantly. Chen and Wang [14] studied the wear properties of the $\mathrm{TiC} / \mathrm{FeAl}$ cladding layer and found that the sliding friction coefficient which was obtained under different sliding wear conditions is not obvious. It indicated that the friction coefficient of the $\mathrm{TiC} / \mathrm{FeAl}$ coating is not sensitive to changes in load and sliding speed, a similar result to this research.

The improvement in wear resistance of S0 coating is a result of the appearance of strengthening phases such as $\mathrm{Cr}_{1.12} \mathrm{Ni}_{2.88}$ which are uniformly distributed in the coating and slows down the wear process of the coating. In addition, the solid solution strengthening and fine-grain strengthening make the microhardness improve and therefore enhance the wear resistance. S0 coating consists of $\gamma$-Co dendrites as the main constituent phase, and there are network cocrystals between these dendrites. The solid solution strengthening and the network of eutectic framework mainly reflect its wear resistance. However, because the hardness of the S0 coating is similar to that of the friction parts and its eutectic structure is distributed in a network, during the high-stress wear process, the brittle network eutectic is prone to stress concentration, which causes spalling pits $[4,5]$.

3.6. Effect of Temperature on Friction and Wear Performance of Co-Based Alloy Coating. The effect of temperature on the coefficient of friction of the S0 coating is shown in Figure 9. The temperature has a great influence on the friction coefficient of the friction pair. The friction coefficient oscillates as the temperature rises. From room temperature to $200^{\circ} \mathrm{C}$, the friction coefficient improves as the temperature increases. From $200^{\circ} \mathrm{C}$ to $600^{\circ} \mathrm{C}$, the friction factor experiences a decline as the temperature goes up. Finally, from $600^{\circ} \mathrm{C}$ to $700^{\circ} \mathrm{C}$, the friction coefficient enhances as the temperature climbs up. At room temperature, $200^{\circ} \mathrm{C}$, and $700^{\circ} \mathrm{C}$, the friction pair has a large friction coefficient. The friction coefficient depends on the state of the friction surface. If the friction surface has large stiffness, low roughness, and no interaction with the abrasive metal, it will have a low friction coefficient.

Due to the increase in temperature and the effect of frictional heat, the temperature of the friction surface goes up, which often causes the oxidation of the friction surface. At lower temperatures, the presence of an oxide film on the friction surface of the friction pair is beneficial to prevent adhesive wear. As the temperature increases, severe oxidation occurs, and oxidative wear and shedding oxide act as abrasives, which produce secondary wear on the friction pair and reduce the wear performance of the friction pair. If the friction pair is softened, it may cause a sudden change in tribological properties. 


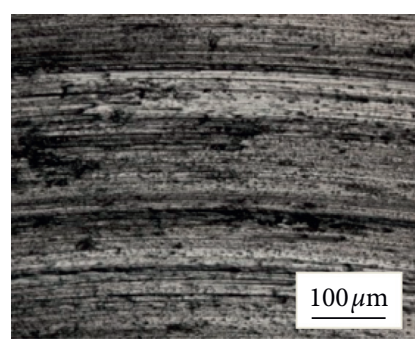

(a)

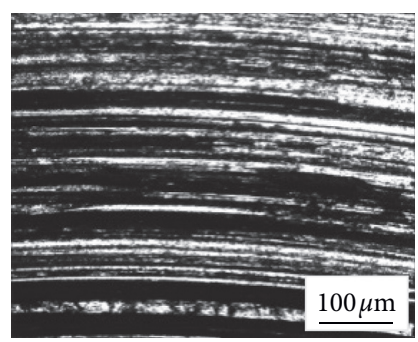

(e)

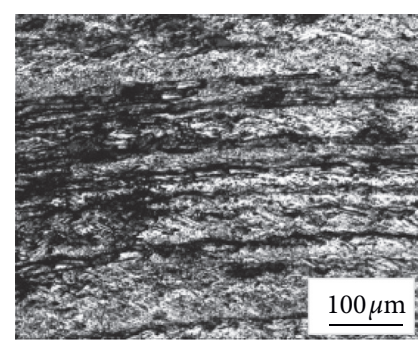

(b)

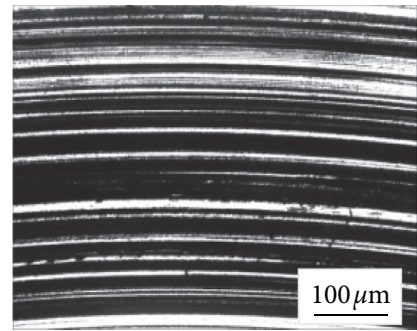

(f)

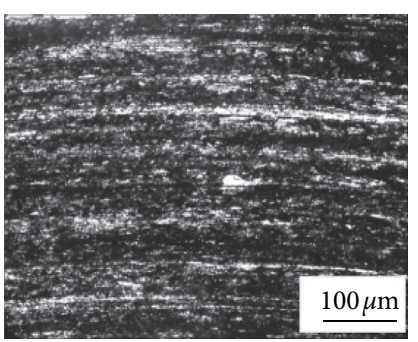

(c)

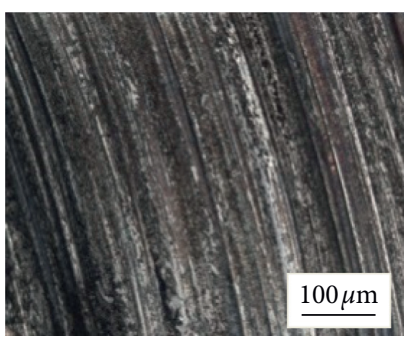

(g)

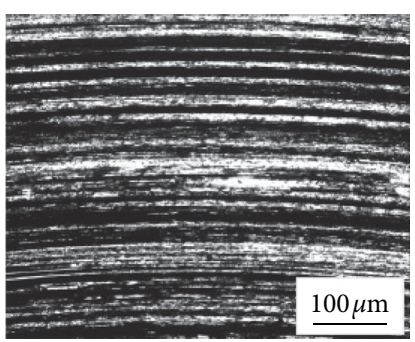

(d)

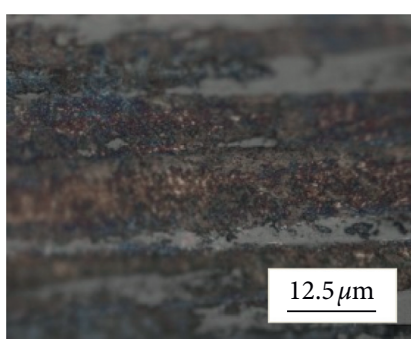

(h)

Figure 10: Worn morphologies of the S0 cladding at different temperatures: (a) room temperature; (b) $200^{\circ} \mathrm{C}$; (c) $300^{\circ} \mathrm{C}$; (d) $400^{\circ} \mathrm{C}$; (e) $500^{\circ} \mathrm{C}$; (f) $600^{\circ} \mathrm{C}$; (g) $700^{\circ} \mathrm{C}$; (h) $700^{\circ} \mathrm{C}$ with high magnification.

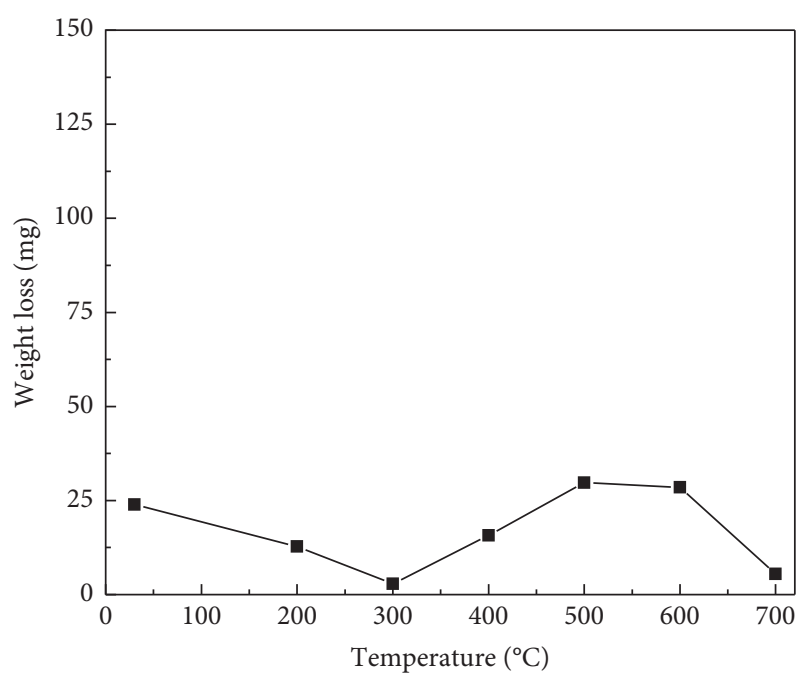

FIGURE 11: Effect of temperature on the wear weight losses of S0 coating.

Figure 10 shows the friction and wear morphology of the So coating at different temperatures. From room temperature to $700^{\circ} \mathrm{C}$, the wear scars of the S0 coating are getting deeper. Especially at $700^{\circ} \mathrm{C}$, the surface of the So coating is dark yellow, which indicates that the S0 coating is severely oxidized [14]. At $500^{\circ} \mathrm{C}, 600^{\circ} \mathrm{C}$, and $700^{\circ} \mathrm{C}$, the worn surface has deep concave resistance.

The analysis of the wear of the S0 sample is shown in Figure 11. It can be seen that when the temperature increases from room temperature to $300^{\circ} \mathrm{C}$, the wear weight losses reduce. From $300^{\circ} \mathrm{C}$ to $600^{\circ} \mathrm{C}$, the wear weight increased. As the temperature rises above $600^{\circ} \mathrm{C}$, the wear weight losses reduced again.
3.7. Effect of Temperature on Friction and Wear Performance of $\mathrm{TiC} / \mathrm{Co}$-based Composite Coating. Figure 12 presents the effect of temperature on the friction coefficient of the S2 coated pin-disk friction pair. The friction coefficient fluctuates around 0.4 on increasing the temperature. The temperature has a negligible influence on the friction coefficient of the friction pair. From room temperature to $700^{\circ} \mathrm{C}$, the friction pair has a relatively stable friction coefficient. Especially at $600^{\circ} \mathrm{C}$ and $700^{\circ} \mathrm{C}$, the friction coefficient of S2 coating remained unchanged.

Figure 13 shows the friction and wear morphology of the S2 coating at different temperatures. From room temperature to $700^{\circ} \mathrm{C}$, the wear scar of the $\mathrm{S} 2$ coating is getting deeper than $\mathrm{S} 0$ coating. At $600^{\circ} \mathrm{C}$ and $700^{\circ} \mathrm{C}$, the wear surface has a deep concave resistance. In addition, at $700^{\circ} \mathrm{C}$, the surface of the S2 coating shows a small amount of blue particles.

The analysis of the wear weight losses of the lower sample is shown in Figures 14 and 15. Generally, the wear weight losses rise on improving the temperature. The wear weight losses on the specimen increase from room temperature to $300^{\circ} \mathrm{C}$, and then it decreases and rises again. The lower sample is $\mathrm{Cr} 12 \mathrm{MoV}$ cold work die steel, which will soften at high temperature, while the S2 sample has better heat resistance and can keep the material performance stable. In the friction process, the friction mechanism is mainly based on the cutting of hard materials to soft materials, leading to sudden changes in friction performance, which makes the friction and wear process unable to proceed normally. At $800^{\circ} \mathrm{C}$, the lower sample is severely abraded; although the wear time is reduced by half, the wear amount is about 10 times than that at $700^{\circ} \mathrm{C}$, as presented in Figure 16. 


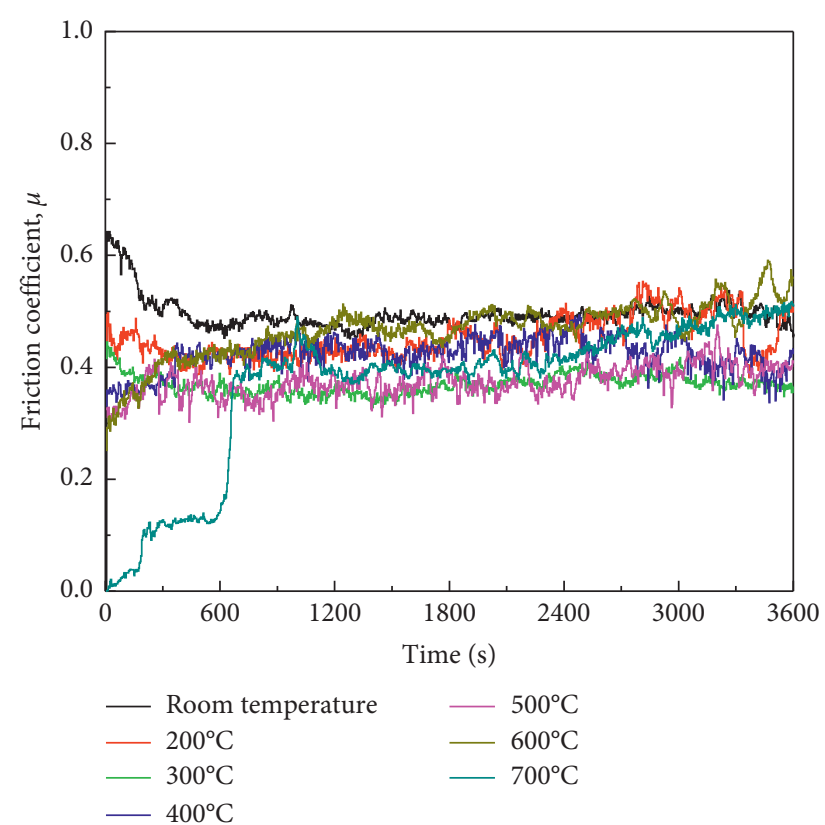

(a)

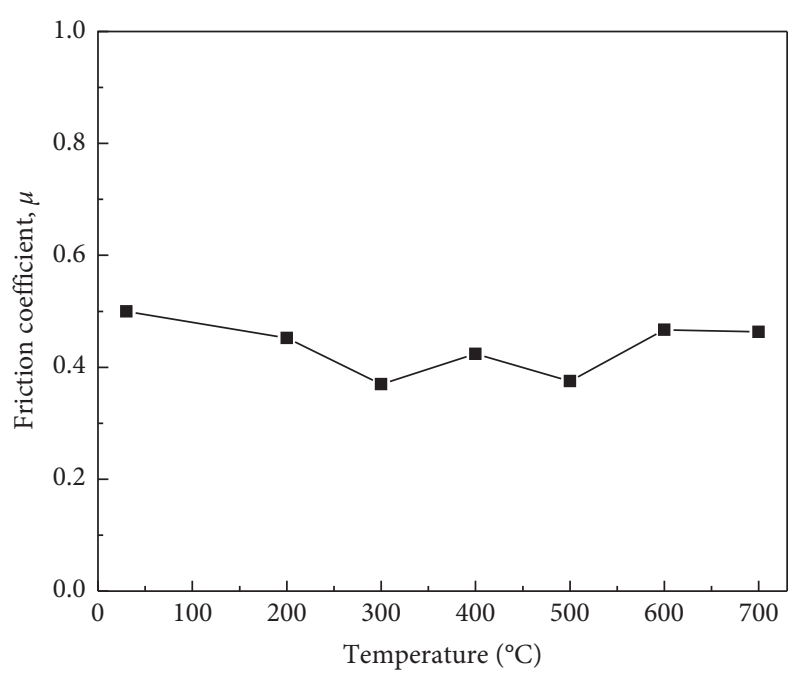

(b)

Figure 12: Friction coefficients of $\mathrm{S} 2$ coating at various temperatures: (a) friction coefficient from room temperature to $700^{\circ} \mathrm{C}$; (b) average coefficient.

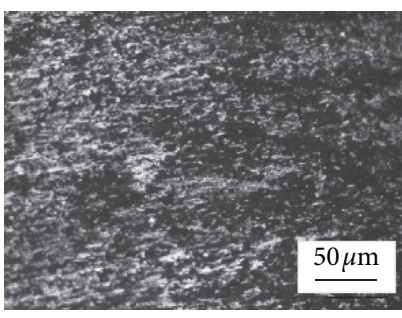

(a)

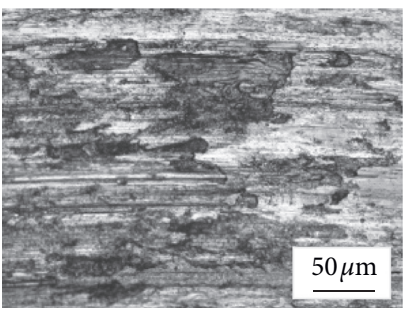

(e)

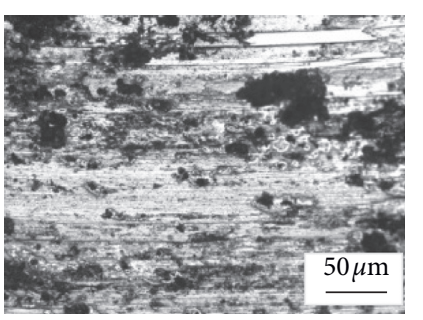

(b)

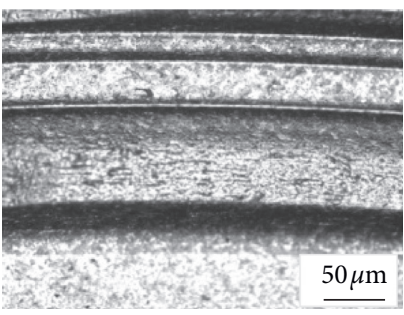

(f)

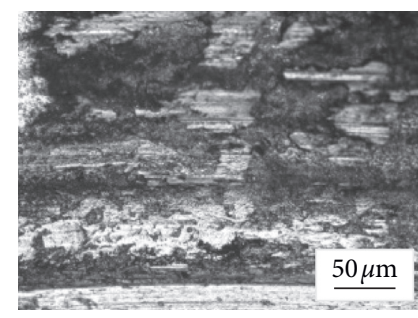

(c)

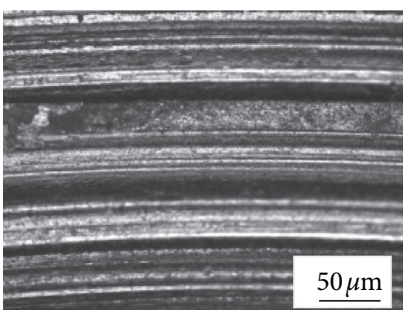

(g)

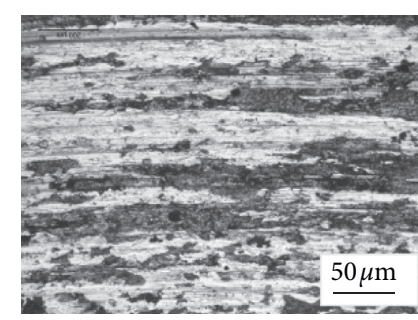

(d)

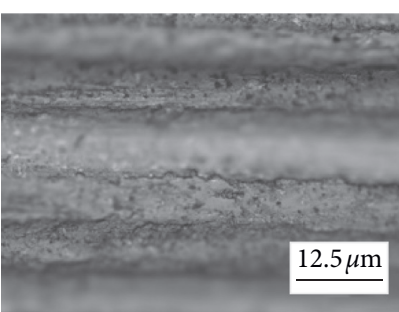

(h)

Figure 13: Worn morphologies of the S2 cladding at different temperatures: (a) room temperature; (b) $200^{\circ} \mathrm{C}$; (c) $300^{\circ} \mathrm{C}$; (d) $400^{\circ} \mathrm{C}$; (e) $500^{\circ} \mathrm{C}$; (f) $600^{\circ} \mathrm{C}$; (g) $700^{\circ} \mathrm{C}$; (h) $700^{\circ} \mathrm{C}$ with high magnification.

The bonding between the coating and the substrate plays an important role in the mechanical characteristics of the samples. Induced residual stress is an important factor that strongly affects the mechanical properties of the cladding layer. Especially, too high-induced residual stress may cause the microcrack or fracture during working [36]. In this paper, the laser cladding parameters are selected so that the achieved cladding layer is well-connected to the substrate, as shown in BZ in Figure 4. Moreover, the friction test and the morphology of the coating after the friction test also shows the good bonding between the coating and the substrate, as shown in Figures 10, 13, and 16. These results indicate the well-bonding between the coating and the substrate and the minor affection of the induced residual stress. Furthermore, the level of the induced residual stress is often rather low, as they are relieved during the cyclic heating and cooling in the laser cladding process [37]. Moreover, the induced residual stress mainly affects the strength of the coating through the modulus of elasticity [38]. The elastic modulus values of $\mathrm{H} 13$ steel and Co are $210 \mathrm{GPa}$, and $211 \mathrm{GPa}$, respectively, which is 


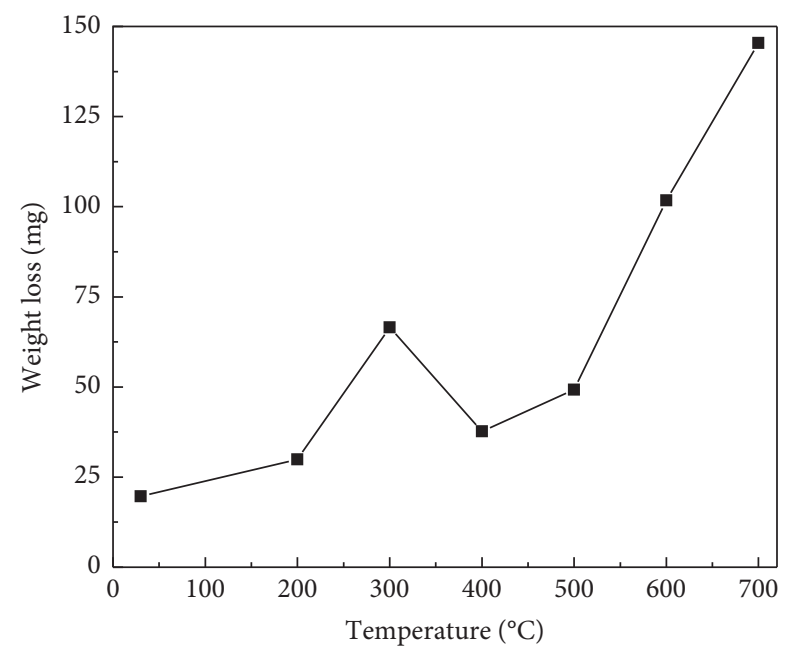

FIgURE 14: Effect of temperature on the wear weight losses of lower specimen.

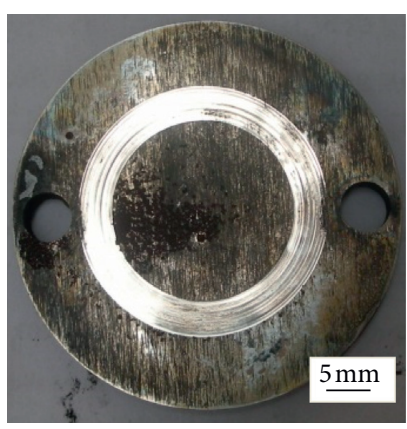

(a)

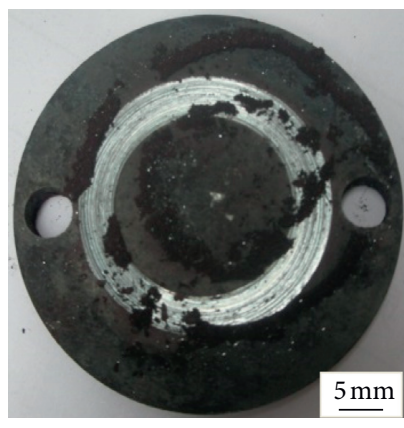

(e)

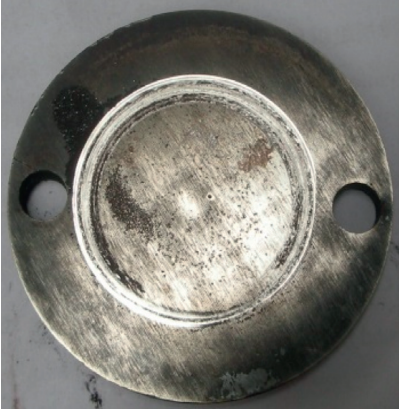

(b)

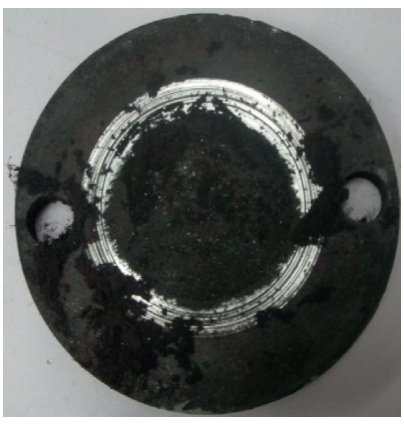

(f)

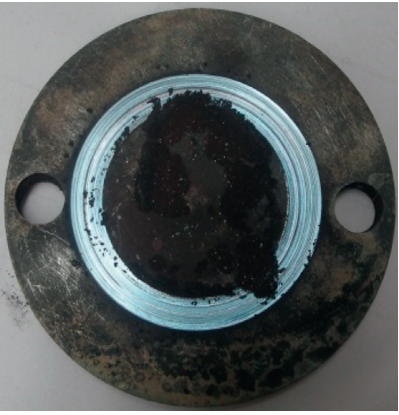

(c)

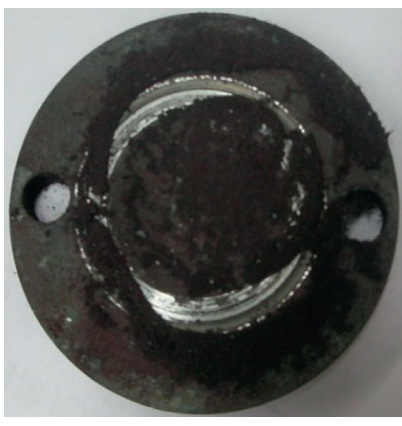

(g)

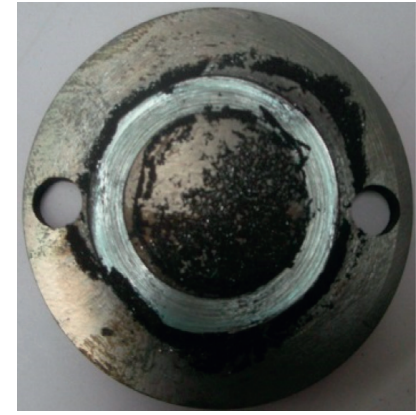

(d)

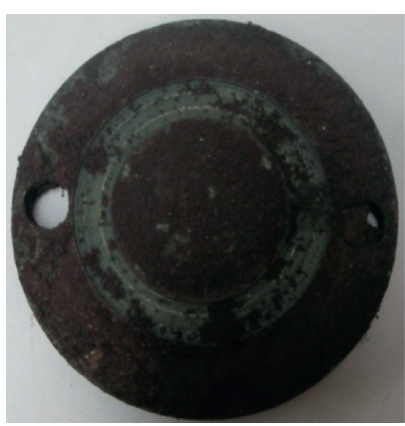

(h)

Figure 15: The wear morphologies of lower specimen at different temperatures: (a) room temperature; (b) $200^{\circ} \mathrm{C}$; (c) $300^{\circ} \mathrm{C}$; (d) $400^{\circ} \mathrm{C}$; (e) $500^{\circ} \mathrm{C}$; (f) $600^{\circ} \mathrm{C}$; (g) $700^{\circ} \mathrm{C}$; (h) $800^{\circ} \mathrm{C}$.

very close to each other. This is why Co-based alloys can create a high-quality coating on the H13 steel substrate [39-41].

\section{Analysis of Friction and Wear Mechanism at Room Temperature and High Temperature}

4.1. Coefficient of Friction and Wear Loss. Because S3 coating is not well combined with $\mathrm{H} 13$ substrate, the test of the friction and wear performance only selects $\mathrm{H} 13$ steel and S0, S1, and S2 samples. The maximum working temperature of hot-work tool steel is $700^{\circ} \mathrm{C}$, so the maximum testing temperature is chosen as $700^{\circ} \mathrm{C}$. In a certain working environment, the stability of the laser cladding layer decides its performance. Therefore, research on the microstructure and properties of the cladding layer at high temperatures is significantly important.

Figure 17 shows the friction coefficient-time curve of $\mathrm{H} 13$ steel and S0, S1, and S2 samples at room temperature and $700^{\circ} \mathrm{C}$. It can be seen that, at room temperature, the friction coefficients of $\mathrm{H} 13$ steel and S0, S1, and S2 slightly fluctuate around about $0.5(0.542,0.501,0.569$, and 0.508 , respectively). However, at $700^{\circ} \mathrm{C}$, the friction coefficients of H13 steel and S1 strongly oscillate around 0.623 and 0.619 , 


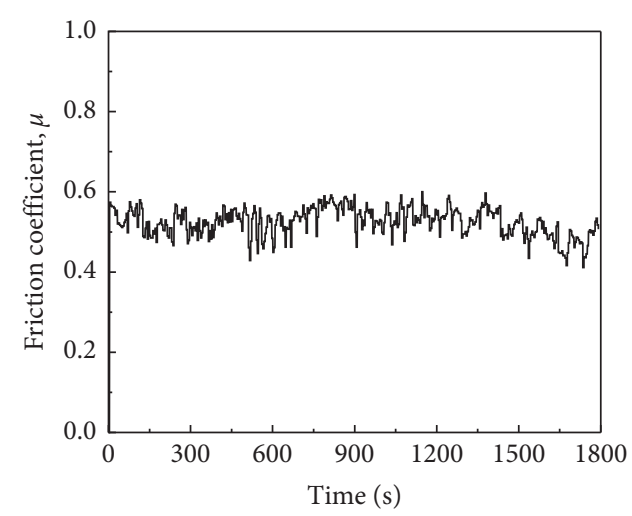

(a)

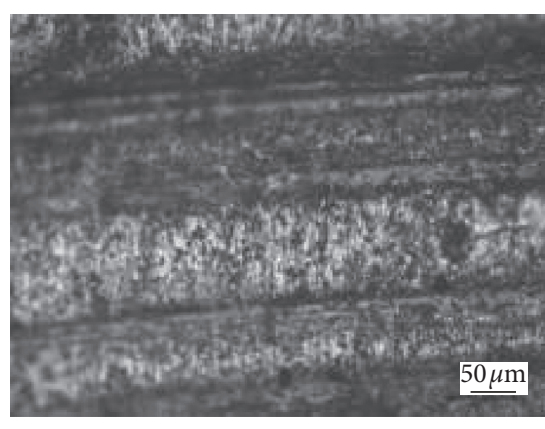

(b)

Figure 16: Friction coefficient and worn morphology of S2 coating at $800^{\circ} \mathrm{C}$.

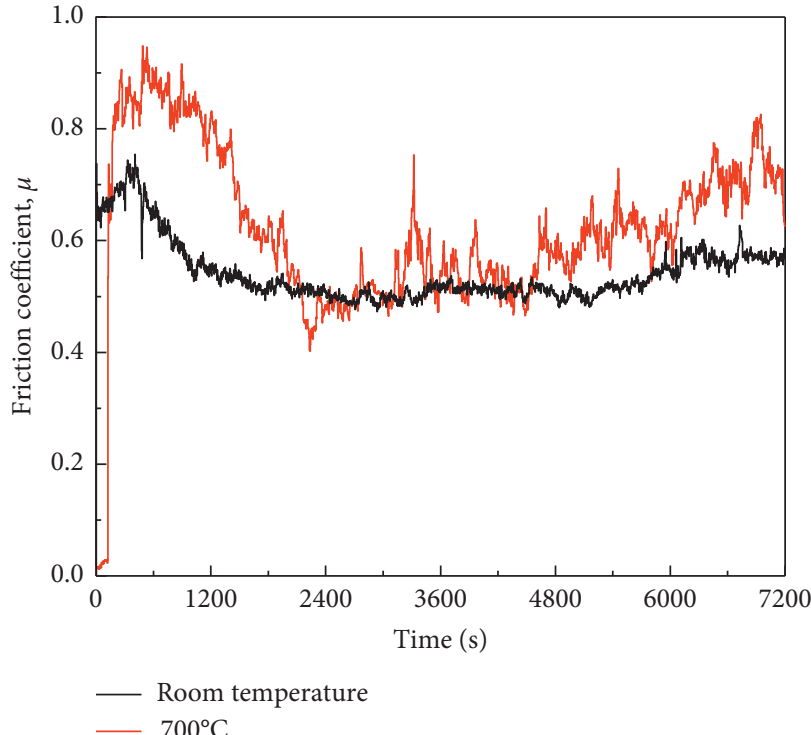

(a)

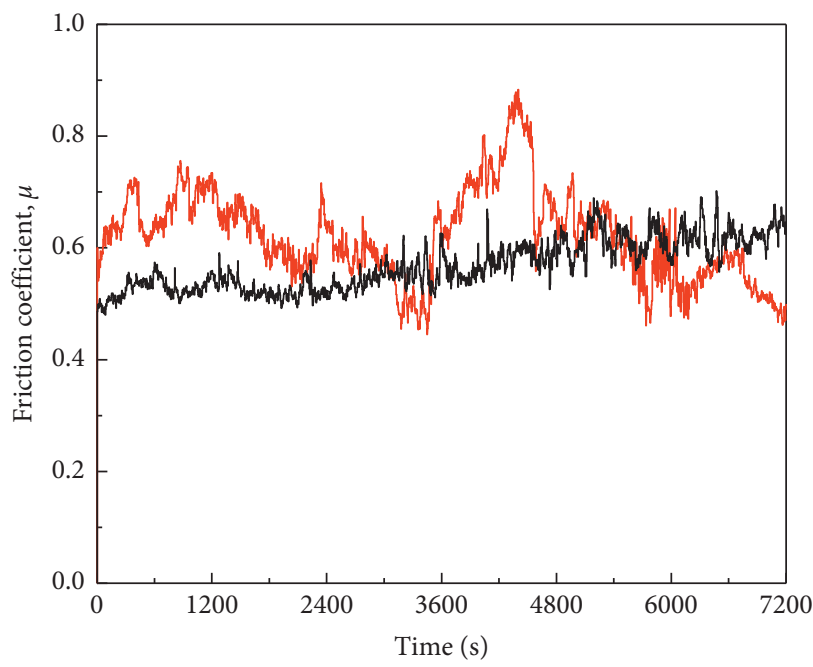

Room temperature $700^{\circ} \mathrm{C}$

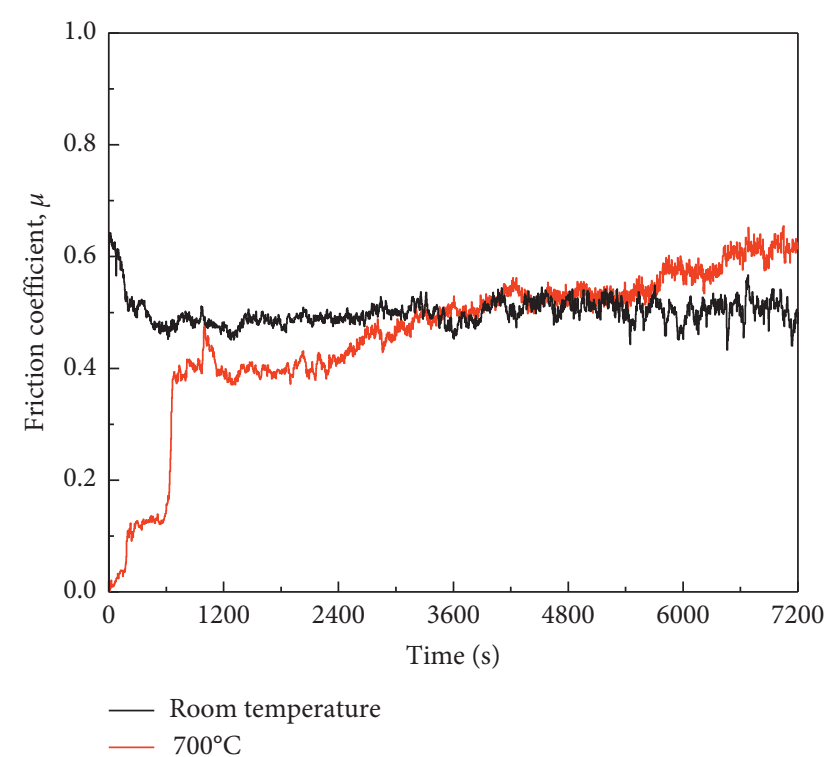

(b)

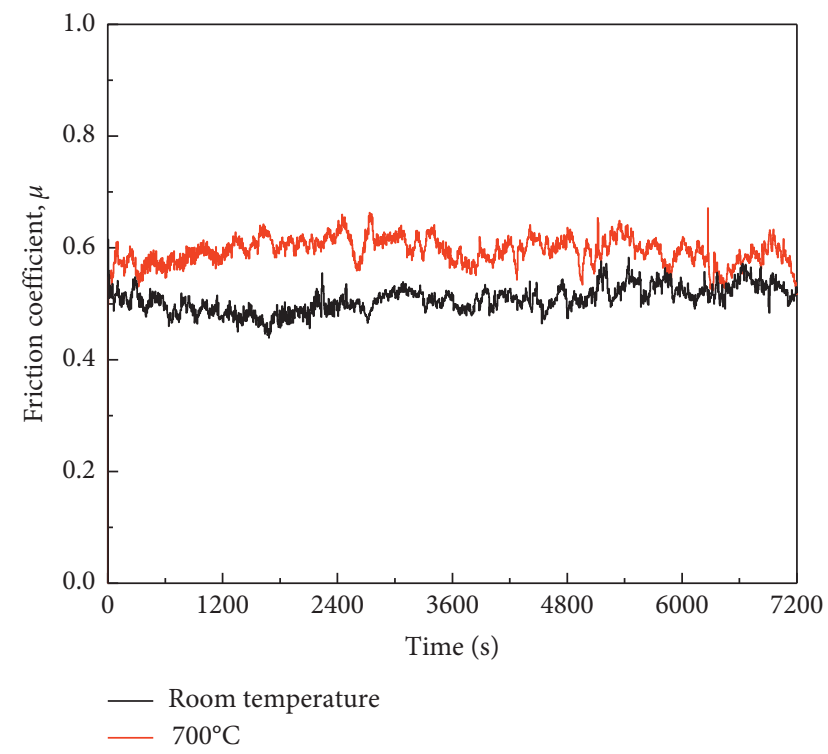

(d)

FIGURE 17: Friction coefficient vs. time curves of $\mathrm{H} 13$ steel and coatings at room temperature and $700^{\circ} \mathrm{C}$ : (a) $\mathrm{H} 13$ steel; (b) S0 coating; (c) S1 coating; (d) S2 coating. 
respectively. The friction coefficient of S0 shows a rapid upward trend. Initially, the friction coefficient is small due to the presence of an oxide film on the surface. However, after $10 \mathrm{~min}$, the oxide film was worn through, and there was a tendency to change from a weak wear state to a severe wear state.

Under the same test conditions, the friction coefficient of S2 coating is very stable. This value is rather high, indicating that, after adding TiC, the wear resistance of the coating is significantly improved. The wear resistance of S0 coating is mainly based on the strengthening effect of the solid solution and the newly $\mathrm{Cr}_{1.12} \mathrm{Ni}_{2.88}$ reinforcement phase. They are uniformly distributed in the coating, having the effect of increasing durability. Besides, their fine microstructure also helps improve the hardness of S0. The hardness of the S0 sample is also as high as the other samples. However, the microstructure of Co50 alloy is characterized by a eutectic structure existing in the form of networks [3]. Therefore, under the effect quite high of the stresses in the friction process, the brittleness of organizations of this grid-like form easily creates concentrated stresses, from which microcracks and peels can easily appear.

Moreover, during the decomposition process of $\mathrm{TiC}$ particles, they could combine with other molten elements to product perinatal dendrite solid solution [4]. S2 coating is mainly composed of initially $\mathrm{TiC}$, in situ $\mathrm{TiC}, \mathrm{Cr}_{2} \mathrm{Ni}_{3}$, and $\gamma$-Co solid solution. These solutions are formed and spread evenly on the fine, small dendrite and eutectic [5], therefore, increasing durability for cohesion between these microstructures and improving the durability and wear resistance of the coating.

In addition, the S2 sample does not show plastic deformation, and its wear mechanism is mainly the adhesion type. In addition, the hardness of S2 is higher than S0, minimizing the surface deformation and thus delaying the time of cracking formation as well as its development speed. These effects result in reducing the risk of cracks failure. The friction coefficient of S2 was stable with a quite high value. Candel et al. [7] show that, when the laser beam's power density increases, the wear resistance is almost unchanged. Due to the positive influence of increasing the $\mathrm{TiC}$ concentration, contributing to the increase in the growth time of $\mathrm{TiC}$ in $\gamma$-Co, thereby, the sample possesses a rather smooth friction surface.

By adding an appropriate amount of $\mathrm{TiC}$, the wear resistance of the coating has been majorly improved. After laser cladding treatment, the hardness of the coating surface increased, which can reduce the deformation of the coating surface under the force, delay the crack initiation time, and reduce the expansion speed.

In order to further analyze the friction and wear properties of the coating, Table 6 gives the weight loss of $\mathrm{H} 13$ steel and S0, S1, and S2 coatings at room temperature and $700^{\circ} \mathrm{C}$. At room temperature, the average weight loss of $\mathrm{H} 13$ steel and S0 coating is $27.8 \mathrm{mg}$ and $23.9 \mathrm{mg}$, respectively. At the same conditions, the average weight loss of S1 and S2 coatings reduced to $19.6 \mathrm{mg}$ and $18.0 \mathrm{mg}$, respectively. It means that, after laser cladding treatment, the wear resistance of H13 steel has been significantly improved, and S1
TABLE 6: Wear weight losses of the samples in the friction-wear test at room temperature and $700^{\circ} \mathrm{C}$.

\begin{tabular}{lccccc}
\hline \multirow{2}{*}{ Condition } & \multirow{2}{*}{ Sample } & \multicolumn{5}{c}{ Wear weight loss $(\mathrm{mg})$} \\
& & H13 steel & S0 & S1 & S2 \\
\hline \multirow{2}{*}{ Room temperature } & Coating & 27.8 & 23.9 & 19.6 & 18.0 \\
& Cr12MoV & 40.6 & 4.3 & 8.8 & 14.3 \\
\hline \multirow{2}{*}{$700^{\circ} \mathrm{C}$} & Coating & 3.0 & 5.5 & 5.2 & 5.0 \\
& Cr12MoV & 4989.7 & 65.1 & 273.0 & 360.5 \\
\hline
\end{tabular}

and S2 coatings have a better wear resistance than S0 coatings. This is because TiC/Co-based cladding has a higher hardness. During the wear process, when the particles on the friction parts meet the hard phase in the coating, the forming scratches are shallower, smaller, or even terminated. Therefore, the cladding sample showed a stronger wear resistance ability, and its wear weight loss was smaller.

At $700^{\circ} \mathrm{C}$, the wear weight loss of $\mathrm{H} 13$ steel is only $3.0 \mathrm{mg}$, which is less than that of S0, S1, and S2 coatings. This is because the peeled metal chips are hot-pressed and could be welded to form larger pieces during the wear process. Moreover, abrasive particles and exfoliated metal will also adhere to the coating surface under stress. This also results in the greatest wear resistance on friction parts of $\mathrm{H} 13$ steel. At the same conditions, the wear weight loss of S0, S1, and S2 coatings is about $5.0 \mathrm{mg}$, while the wear weight losses of S1 and S2 friction parts are much 4 and 6 times larger than that of S0 friction parts. Therefore, it can be concluded that S2 has minimal wear weight loss, and the wear resistance is the best.

From the above analysis, surface modification of $\mathrm{H} 13$ steel by laser cladding can highly improve its wear resistance. This is closely related to the hardness, density, and uniformity of the structure and the melting point of the coating. It is generally believed that the main factors affecting the mechanical properties of metal materials are plasticity, hardness, and tensile strength, in which the wear resistance of the surface has a roughly linear relationship with its hardness. The analysis of the weight loss under various conditions shows that the higher the hardness of the material, the smaller the weight loss. S1 and S2 have a higher wear resistance. However, since the strengthening of carbides is not effective as significant as other second-phase particles, therefore, their weight loss is almost the same.

The wear resistance of S1 composite coating is higher than that of S0 coating. The main reason is that, during the process of laser cladding, $\mathrm{TiC}$ which melts and precipitates is formed with the matrix elements to generate new carbides. The unmelted or semimelted $\mathrm{TiC}$ particles are diffusely distributed in the cladding area and play a hard reinforcement role. $\mathrm{S} 1$ coating is composed of unmelted $\mathrm{TiC}$, TiC in situ, $\mathrm{TiCo}_{3}, \mathrm{Cr}_{2} \mathrm{Ni}_{3}$, and $\mathrm{Cr}-\mathrm{Ni}-\mathrm{Fe}-\mathrm{C}$ solid solution with a fine eutectic structure. In addition, the hardness of S1 composite coating is higher than that of S0 coating, and the carbides are finer distributed. In the fine dendrite and eutectic structure, TiC plays as the core-shaped radial carbide which enhances the bonding between the coating structures; thereby, its wear resistance is effectively upgraded.

S2 coating has better antiwear performance as their TiC content is higher. When the S2 coating and the friction part are 


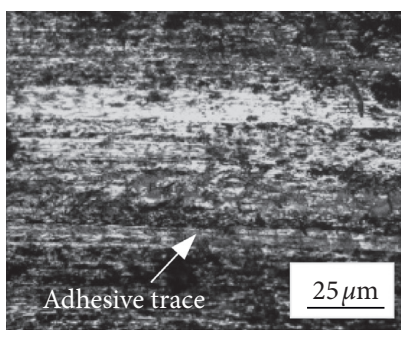

(a)

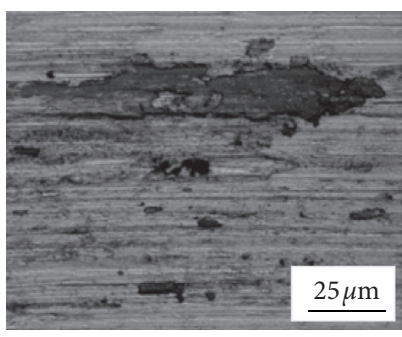

(b)

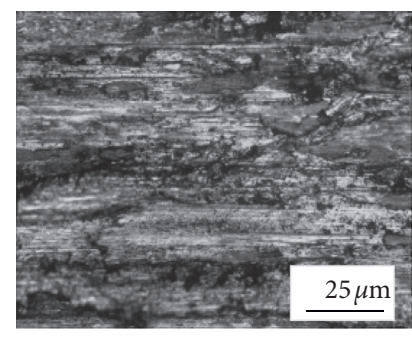

(c)

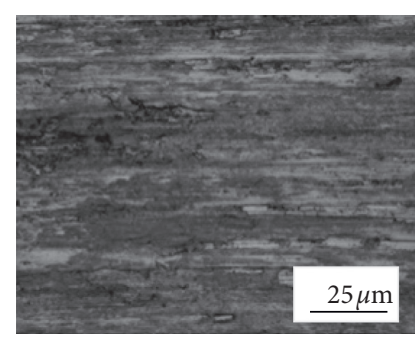

(d)

FIGURE 18: Worn morphologies of samples at room temperature: (a) H13 steel; (b) S0 coating; (c) S1 coating; (d) S2 coating.

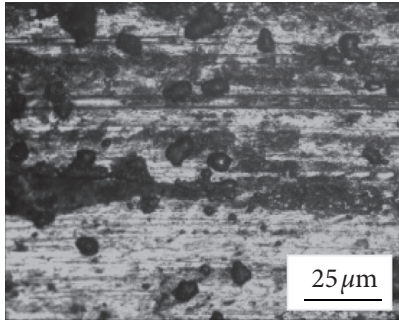

(a)

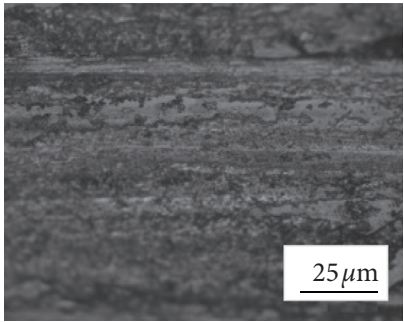

(b)

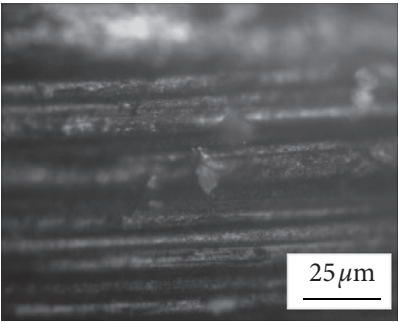

(c)

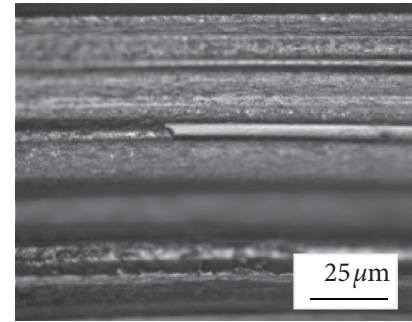

(d)

FIGURE 19: Worn morphologies of samples at $700^{\circ} \mathrm{C}$ : (a) H13 steel; (b) S0 coating; (c) S1 coating; (d) S2 coating.

facing each other, as S2 is mainly composed of carbides, the friction parts are easily embedded in the softer $\gamma$-Co solid solution. In addition, during the ploughing process, friction parts encounter fewer obstacles; as a result, a deeper furrow is formed.

Secondly, the hardness of the S2 sample is higher than S1 one. In the wear process, increasing the coating hardness can reduce the deformation of the coating surface, decrease the propagation speed, postpone crack initiation time, and delay the chance in crack nucleation. However, the friction coefficient of the S2 coating is higher than S1. It may be due to the existence of hard phases in S2. Under high stress for a long time, the massive hard phase flakes and peels; thus, wear resistance is reduced [6].

4.2. Friction and Wear Morphology. Figures 18 and 19 show the friction and wear morphology of H13 steel and S0, S1, and S2 coatings at room temperature and $700^{\circ} \mathrm{C}$. At room temperature, H13 steel and S0, S1, and S2 coatings have fine and shallow scars. No cracks can be found, and the surfaces only have a small amount of melted adhesion. The H13 steel has the deepest wear scars and furrows. The wear surfaces of the S0 and S1 coatings have polishing plastic deformation and spalling pits with slight furrows. When observing the plastic deformation area, the interior of the plastic deformation area is smooth. This is the result of the adhesive wear effect, as seen in Figure 20(a). The wear surface of the S2 coating is smoother than S1, and there is almost no obvious deformation. However, there are also spalling areas slight furrows and slight adhesive wear, as shown in Figure 20(c). Therefore, at room temperature, the wear mechanism of $\mathrm{H} 13$ steel is mainly brittle spalling and ploughing, while the wear mechanism of S0, S1, and S2 coatings is mainly brittle spalling, adhesive wear, and ploughing.
At $700^{\circ} \mathrm{C}$, the pits on the worn surface are deep and small, and scratches with raised edges are flattened, as shown in Figure 20(d). At this time, the friction coefficient is large, but the wear amount is small. S1 and S2 have deeper wear scars than $\mathrm{S} 0$, and the surface of S0 is dark yellow, while only a few blue particles are seen on the surfaces of S1 and S2. The S0 coating has the most severe oxidation. This indicates that S1 and S2 are relatively slightly oxidized, and after adding $\mathrm{TiC}$, the wear resistance of the coating is significantly improved.

These above experiments indicate that the S0, S1, and S2 coatings significantly improve the wear resistance of the H13 steel substrate. This H13 steel surface has a lower hardness and poor wear resistance of the substrate. The surface is prone to plastic deformation or even cracks due to severe extrusion. At the same time, the peeling metal chips will also be hotpressed and welded to form larger abrasives particles during the wear process. Under stress, these larger pieces and abrasive particles without sharp edges produce severe plastic deformation and obvious furrows on the wear surface [1-3].

4.3. XRD Analysis of Friction and Wear Surface. The existence of the coating compounds is studied by using the XRD method. At room temperature, from S0 to S2 samples with different amounts of $\mathrm{TiC}$ in the coating, some phases appear such as $\gamma$-Co, $\mathrm{TiC}, \mathrm{Co}_{3} \mathrm{Ti}, \mathrm{CoO}$, and $\mathrm{FeO}$, as shown in Figure 21(a). We can ignore $\mathrm{FeO}$ because it comes from the friction disc and the precursors of the coating consist only $\mathrm{TiC}$ and $\mathrm{Co50}$. $\gamma$-Co, $\mathrm{TiC}, \mathrm{Co}_{3} \mathrm{Ti}$, and $\mathrm{CoO}$ compounds appear in the coating because of the high-temperature effect of the laser treatment on $\mathrm{TiC}$ and Co50 in the atmospheric condition. $\mathrm{CoO}$ appears due to the oxygen in the atmosphere oxidizes Co. The existence of $\mathrm{Co}_{3} \mathrm{Ti}$ indicates strong 


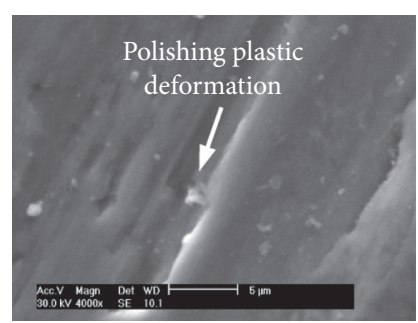

(a)

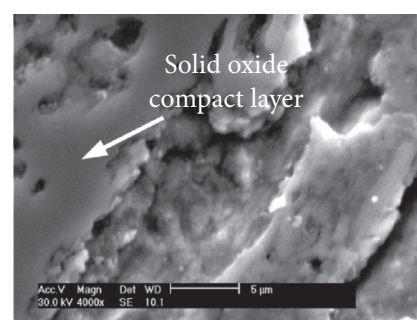

(b)

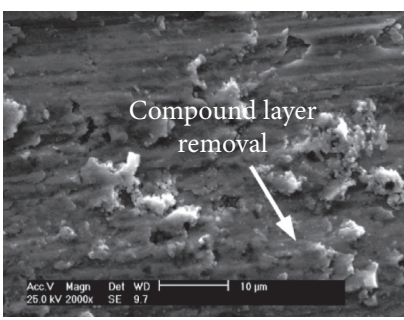

(c)

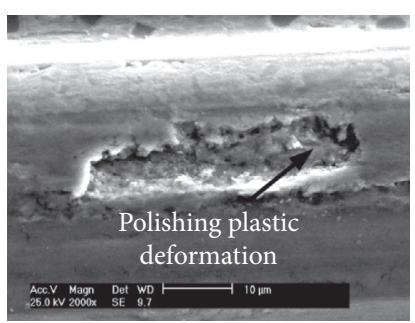

(d)

Figure 20: Worn morphologies of S0 and S2 coatings at room temperature and $700^{\circ} \mathrm{C}$ : (a) polishing plastic deformation in S0 coating at room temperature; (b) solid oxide compact layer in S0 coating at $700^{\circ} \mathrm{C}$; (c) compound layer removal in $\mathrm{S} 2$ coating at room temperature; (d) pitting corrosion in $\mathrm{S} 2$ coating at $700^{\circ} \mathrm{C}$.

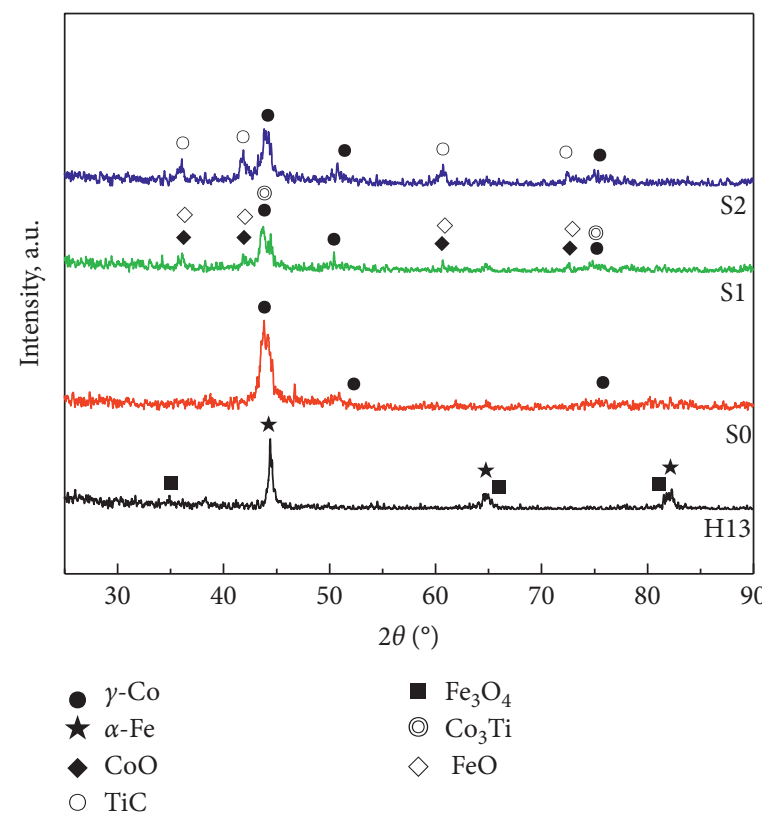

(a)

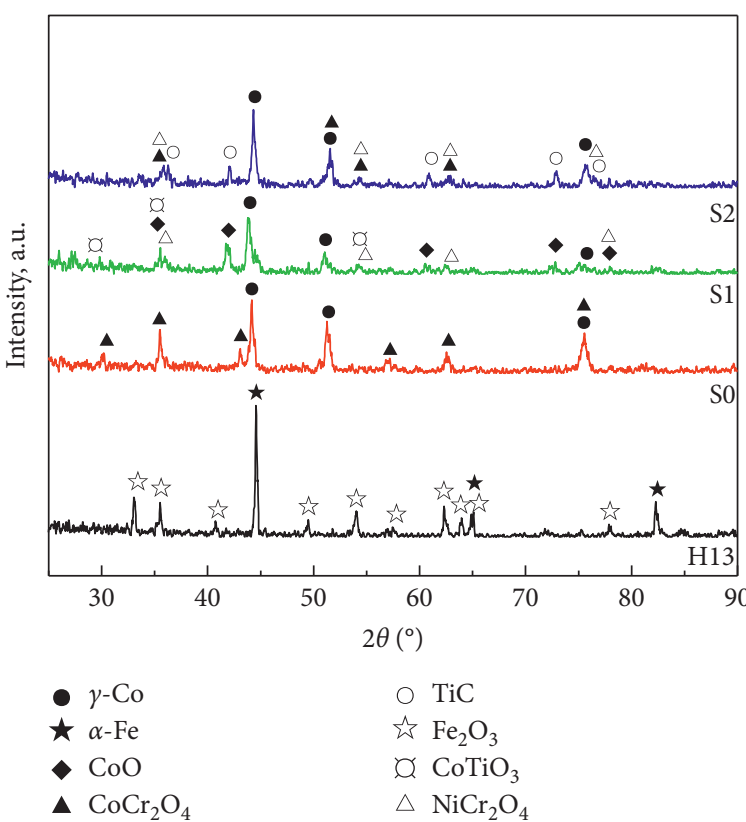

(b)

Figure 21: XRD patterns of $\mathrm{H} 13$ steel and S0, S1, and S2 coatings (a) at room temperature and (b) $700^{\circ} \mathrm{C}$.

interaction and diffusion between $\mathrm{TiC}$ and Co powders. The microhardness number of $\mathrm{Co}_{3} \mathrm{Ti}$ is higher than Co but much lower than TiC. Therefore, the amount of this $\mathrm{Co}_{3} \mathrm{Ti}$ phase could affect the microhardness of the cladded surface.

In order to further analyze the wear mechanism of the coating, Figure 21 shows the XRD spectrum of the wear surface of $\mathrm{H} 13$ steel and S0, S1, and S2 coatings at room temperature and $700^{\circ} \mathrm{C}$. At room temperature, $\mathrm{Fe}_{3} \mathrm{O}_{4}$ oxides appear in $\mathrm{H} 13$ steel samples, $\mathrm{CoO}$ and $\mathrm{FeO}$ oxides exist in $\mathrm{S} 1$ samples, while oxides are not present in $\mathrm{S} 0$ and $\mathrm{S} 2$ samples. At $700^{\circ} \mathrm{C}, \mathrm{H} 13$ steel sample consists of $\mathrm{Fe}_{2} \mathrm{O}_{3}$ oxides, and there is a large amount of $\mathrm{CoCr}_{2} \mathrm{O}_{4}$ oxide in the $\mathrm{S} 0$ sample. S1 sample contains $\mathrm{CoO}, \mathrm{CoTiO}_{3}$, and a small amount of $\mathrm{NiCr}_{2} \mathrm{O}_{4}$ oxides, while the $\mathrm{S} 2$ sample appears a large amount of $\mathrm{CoCr}_{2} \mathrm{O}_{4}$ and $\mathrm{NiCr}_{2} \mathrm{O}_{4}$ oxides. The improvement in the surface wear properties of the coatings is closely related to the presence of these oxides. This means that, at $700^{\circ} \mathrm{C}$, the wear mechanism of H13 steel, S0, S1, and S2 coatings is mainly oxidation wear and fatigue wear.
The reason for these phenomena is that, as the temperature rises, the oxidation of the surface sample is intensified. The forming oxide film avoids adhesive wear caused by metal contact and protects the worn surface. However, the oxide film is often brittle and extremely prone to crack initiation and fatigue crack growth under external force; therefore, it is easy to produce fatigue spalling [15]. After the oxide film is fatigued and peeled off, the metal in the peeling area will continue to be oxidized. This is a dynamic wear process where oxidation and spalling are alternate. Observation of the wear morphology of $\mathrm{H} 13$ steel and S0, S1, and S2 samples at $700^{\circ} \mathrm{C}$, it was also found that no cracks were generated on the wear surface. A study by Xiong et al. has shown that, at high-temperature conditions, a dense oxide protective film which can be formed on the material surface and well combined with the substrate can effectively prevent the material from oxidizing. The material's resistance to high-temperature erosion wear will be significantly improved [42]. 
After adding TiC, the strength of the microstructures of S1 and S2 is improved, the grains are refined, and various defects in the coating are reduced. In addition, TiC which has a much higher hardness than the matrix and disperse in the ductile matrix enhances the bonding between phases. When the coating is worn, these TiC particles have an extremely strong resistance to deformation. On the one hand, they can support the load, play a uniform load, and reduce friction and wear, so the friction coefficient changes little and the wear resistance is correspondingly improved. On the other hand, they protect the substrate, and thereby, the wear resistance of S1 and S2 coatings with $\mathrm{TiC}$ particles is significantly improved. In addition, in the laser cladding layer, some $\mathrm{TiC}$ particles are not dissolved; however, there are also some $\mathrm{TiC}$ pyrolysis reactions that generate $\mathrm{TiC}$ in situ. $\mathrm{TiC}$ in situ forms a densely distributed $\mathrm{TiC}$ phase on the substrate surface that is tightly bound with the substrate. The modified layer has a much higher hardness than the substrate, which greatly improves the wear resistance [43].

\section{Conclusions}

(1) The hardness reduces from the coating to the substrate, reaching the highest value at the coating zone. In the HAZ, the hardness reduces rapidly. Increasing the content of $\mathrm{TiC}$ leads to improving the hardness of the coating.

(2) The coatings with $10 \%-20 \% \mathrm{TiC}$ present high-quality surface morphology and macrograph. With $30 \% \mathrm{TiC}$, the hardness reaches a higher hardness but the surface appears to crack. The microstructures of these coatings indicate a well-mixed and well-distribution of the $\mathrm{TiC}$ particle on the Co matrix.

(3) The friction coefficient of H13 steel and Co50 coating reaches the maximum value when the load is $50 \mathrm{~N}$ and mostly decreases with the increase in the load. The wear rates of H13 steel and Co50 coatings mainly increase with the increase in the load. The temperature has a greater influence on the friction coefficient of the Co50 coating. However, the temperature has a small effect on the friction coefficient of the $20 \% \mathrm{TiC}$ coating.

(4) The wear resistance of $20 \% \mathrm{TiC}$ coating is higher than that of $\mathrm{H} 13$ steel, Co50 coating, and $10 \% \mathrm{TiC}$ composite coating. At room temperature, the wear mechanism of the coating is mainly brittle spalling, adhesive wear, and ploughing. At $700^{\circ} \mathrm{C}$, the wear mechanism is mainly oxidation wear and fatigue wear. After laser cladding, the service life of the coated surface could be greatly improved.

\section{Data Availability}

The data used to support the findings of this study are available from the corresponding author upon request.

\section{Conflicts of Interest}

The authors declare that there are no conflicts of interest regarding the publication of this paper.

\section{Acknowledgments}

The authors acknowledge HCMC University of Technology and Education and Kunming University of Technology. They gave them an opportunity to join their team and access the laboratory and research machines. Without their appreciated support, it would not be possible to conduct this research.

\section{References}

[1] M.-x. Wei, S.-q. Wang, L. Wang, X.-h. Cui, and K.-m. Chen, "Selection of heat treatment process and wear mechanism of high wear resistant cast hot-forging die steel," Journal of Iron and Steel Research International, vol. 19, no. 5, pp. 50-57, 2012.

[2] M. X. Wei, F. Wang, S. Q. Wang, and X. H. Cui, "Comparative research on the elevated-temperature wear resistance of a cast hot-working die steel," Materials \& Design, vol. 30, no. 9, pp. 3608-3614, 2009.

[3] C. Xianghong, W. Shuqi, J. Qichuan, and C. Kangmin, "Research on thermal wear of cast hot forging die steel modified by rare earths," Journal of Rare Earths, vol. 25, no. 1, pp. 88-92, 2007.

[4] Y. M. Zhao, J. L. Wang, and J. W. Mou, "Microstructures and properties of Co-based alloy coatings prepared on surface of H13 steel," China Welding, vol. 19, no. 3, pp. 41-44, 2010.

[5] Ye. Si-you, J.-y. Liu, and W. Yang, "Quality of H13 alloy coating on H13 steel prepared by laser cladding," Surface Technology, vol. 8, no. 44, pp. 81-87, 2015.

[6] J. S. Guo, J. W. Su, and C. S. Guang, "Research on impact wear resistance of in situ reaction TiCp/Fe composite," Wear, vol. 269, no. 3-4, pp. 285-290, 2010.

[7] J. J. Candel, V. Amigó, J. A. Ramos, and D. Busquets, "Sliding wear resistance of TiCp reinforced titanium composite coating produced by laser cladding," Surface and Coatings Technology, vol. 204, no. 20, pp. 3161-3166, 2010.

[8] Z.-d. Huang, Q.-k. Cai, J.-p. Niu et al., "Effect of adding ceramic particles on grain refining in low carbon microalloy steel," Journal of Northeastern University (Natural Science), vol. 7, pp. 997-1000, 2009.

[9] Y. You-Wei, W. Bo-Kang, Z.-Y. Fu et al., "In situ fabrication of $\mathrm{TiC}_{\mathrm{p}} / \mathrm{Fe}$ composites by reactions in $\mathrm{Fe}-\mathrm{Ti}-\mathrm{C}$ melt under air condition," Acta Materiae Compositae Sinica, vol. 3, pp. 51$54,2000$.

[10] X. Qian, H. Tong, D. Zhang et al., "Microstructure and performance of laser-cladding Co-based alloy coating on the surface of H13 mold steel," Metallurgical Collections, vol. 5, pp. 1-3, 2011.

[11] S. Song-hua, H. Yi-zhu, Y. Xiao-min et al., "Microstructure and wear-resistance of laser clad Co-based alloy coatings with $\mathrm{B}_{4} \mathrm{C}_{\mathrm{p}}, \mathrm{SiC}_{\mathrm{p}}$," Zhongguo Yousejinshu Xuebao, vol. 13, no. 2, pp. 454-459, 2003.

[12] V. K. Acker, D. Vanhoyweghen, R. Persoons, and J. Vangrunderbeek, "Influence of tungsten carbide particle size and distribution on the wear resistance of laser clad WC/ Ni coatings," Wear, vol. 258, no. 1-4, pp. 194-202, 2005.

[13] E. O. Correa, J. N. Santos, and A. N. Klein, "Microstructure and mechanical properties of WC Ni-Si based cemented carbides developed by powder metallurgy," International Journal of Refractory Metals and Hard Materials, vol. 28, no. 5, pp. 572-575, 2010.

[14] Y. Chen and H. M. Wang, "High-temperature wear resistance of a laser clad $\mathrm{TiC}$ reinforced $\mathrm{FeAl}$ in situ composite coating," 
Surface and Coatings Technology, vol. 179, no. 2-3, pp. 252256, 2004.

[15] H. Kashani, A. Amadeh, and H. M. Ghasemi, "Room and high temperature wear behaviors of nickel and cobalt base weld overlay coatings on hot forging dies," Wear, vol. 262, no. 7-8, pp. 800-806, 2007.

[16] Y. Xiao-hong, H. Wen-xian, S.-g. Qin et al., "Microstructure and wear properties of Co-based composite coatings on $\mathrm{H} 13$ steel surface by laser cladding," Journal of Jilin University (Engineering and Technology Edition), vol. 3, pp. 891-899, 2017.

[17] L. Zhiyuan, Z. Weiyi, N. Dengpan, H. Hao, G. Jiarui, and $\mathrm{X}$. Tao, "Effect of TiN on microstructure and properties of Cobased alloy coating by laser cladding," High Power Laser and Particle Beams, vol. 22, no. 7, pp. 1657-1660, 2010.

[18] S. Song-hua, K. Xu, Y. Xiao-min, and Y.-L. Liu, "Microstructure and wear performance of laser cladding $\mathrm{Cr}_{3} \mathrm{C}_{2} / \mathrm{Co}$ alloy composite coating," Tribology, vol. 26, no. 2, pp. 125-129, 2006.

[19] S. Songhua, X. Yuan, X. Zuo, and Y. Z. He, "Effect of B4C particles on microstructure and wear resistance of Co-based alloy laser cladding," Transactions of The China Welding Institution, vol. 25, no. 3, pp. 61-64, 2004.

[20] Y. Chen and H. M. Wang, "Microstructure and wear resistance of a laser clad $\mathrm{TiC}$ reinforced nickel aluminides matrix composite coating," Materials Science and Engineering, vol. 368 , no. 1-2, pp. 80-87, 2004.

[21] Y. J. Dong and H. M. Wang, "Microstructure and dry sliding wear resistance of laser clad $\mathrm{TiC}$ reinforced $\mathrm{Ti}-\mathrm{Ni}-\mathrm{Si}$ intermetallic composite coating," Surface and Coatings Technology, vol. 204, no. 5, pp. 731-735, 2009.

[22] Y. Chen and H. M. Wang, "Microstructure and wear resistance of laser clad $\mathrm{TiC}$ reinforced $\mathrm{FeAl}$ intermetallic matrix composite coatings," Surface and Coatings Technology, vol. 168, no. 1, pp. 30-36, 2003.

[23] X. H. Wang, M. Zhang, X. M. Liu, S. Y. Qu, and Z. D. Zou, "Microstructure and wear properties of TiC/FeCrBSi surface composite coating prepared by laser cladding," Surface and Coatings Technology, vol. 202, no. 15, pp. 3600-3606, 2008.

[24] R. L. Sun, J. F. Mao, and D. Z. Yang, "Microscopic morphology and distribution of $\mathrm{TiC}$ phase in laser clad NiCrBSiCTiC layer on titanium alloy substrate," Surface and Coatings Technology, vol. 155, no. 2-3, pp. 203-207, 2002.

[25] A. Emamian, S. F. Corbin, and A. Khajepour, "Tribology characteristics of in-situ laser deposition of Fe-TiC," Surface and Coatings Technology, vol. 206, no. 22, pp. 4495-4501, 2012.

[26] A. Emamian, S. F. Corbin, and A. Khajepour, "Effect of laser cladding process parameters on clad quality and in-situ formed microstructure of Fe-TiC composite coatings," Surface and Coatings Technology, vol. 205, no. 7, pp. 2007-2015, 2010.

[27] $\mathrm{X} . \mathrm{Wu}$ and $\mathrm{Y}$. Hong, "Microstructure and mechanical properties at $\mathrm{TiC}_{\mathrm{p}} / \mathrm{Ni}$-alloy interfaces in laser-synthesized coatings," Materials Science and Engineering: A, vol. 318, no. 1-2, pp. 15-21, 2001.

[28] X. Wu and Y. Hong, "Interface structure and distributions of hardness and modulus near interface in $\mathrm{TiC}_{\mathrm{p}} / \mathrm{Ni}$ laser clad coatings," Acta Metallurgica Sinica, vol. 36, no. 3, pp. 282-286, 2000.

[29] Y. Pei, "Laser clad $\mathrm{TiC}_{\mathrm{p}} / \mathrm{Ni}$ alloy functionality gradient coating and its in-situ formation mechanism," Acta Metallurgica Sinica, vol. 34, no. 9, pp. 987-991, 1998.
[30] H.-m. Gao and C. Chao-ying, "Wear property and mechanism of laser cladding TiC-Ni composite coating," Optical Technique, vol. 35, no. 4, pp. 546-548, 2009.

[31] B. Xu, J. Fang, H. Shi, and Z. Xiju, "Effect of TiC content on laser cladding ceramic coatings of Fe-base alloy," Materials for Mechanical Engineering, vol. 22, no. 1, pp. 20-22, 1998.

[32] Y. Pei, Q. Meng, J. Ouyang et al., "Dissolution and precipitation of TiC particles and their distribution in a laser clad 30 vol.-\% $\mathrm{TiC}_{\mathrm{p}} / \mathrm{Ni}$-alloy composite coating," Chinese Journal of Lasers, vol. 22, no. 12, pp. 935-938, 1995.

[33] Y. Li, P. Bai, Y. Wang, J. Hu, and Z. Guo, "Effect of TiC content on $\mathrm{Ni} / \mathrm{TiC}$ composites by direct laser fabrication," Materials \& Design, vol. 30, no. 4, pp. 1409-1412, 2009.

[34] W. Chen, Y. Gao, C. Chen, and J. Xing, "Tribological characteristics of $\mathrm{Si}_{3} \mathrm{~N}_{4}-\mathrm{hBN}$ ceramic materials sliding against stainless steel without lubrication," Wear, vol. 269, no. 3-4, pp. 241-248, 2010

[35] K. Li, Z. Huang, L. Zhang et al., "Influence of $\mathrm{Cr}$ addition on tribological properties of bulk $\mathrm{Fe}_{2} \mathrm{~B}$ under dry friction and water lubrication," Materials Research Express, vol. 5, no. 7, Article ID 076506, 2018.

[36] P. Farahmand and R. Kovacevic, "An experimental-numerical investigation of heat distribution and stress field in single- and multi-track laser cladding by a high-power direct diode laser," Optics \& Laser Technology, vol. 63, pp. 154-168, 2014.

[37] M. Masanta, S. M. Shariff, and A. R. Choudhury, "Evaluation of modulus of elasticity, nano-hardness and fracture toughness of $\mathrm{TiB}_{2}-\mathrm{TiC}-\mathrm{Al}_{2} \mathrm{O}_{3}$ composite coating developed by SHS and laser cladding," Materials Science and Engineering: $A$, vol. 528, no. 16-17, pp. 5327-5335, 2011.

[38] X. Yang, C. Li, Z. Zhang, X. Zhang, and J. Gu, "Effect of cobalt-based coating microstructure on the thermal fatigue performance of AISI H13 hot work die steel," Applied Surface Science, vol. 521, Article ID 146360, 2020.

[39] G. Wang, J. Zhang, R. Shu, and S. Yang, "High temperature wear resistance and thermal fatigue behavior of Stellite-6/WC coatings produced by laser cladding with Co-coated WC powder," International Journal of Refractory Metals and Hard Materials, vol. 81, pp. 63-70, 2019.

[40] M. Muro, J. Leunda, G. Artola, and C. Soriano, "Microstructural tuning of a laser-cladding layer by means of a mix of commercial Inconel 625 and AISI H13 powders," Materials, vol. 12, no. 3, p. 544, 2019.

[41] J. Zhao, Q. Gao, H. Wang et al., "Microstructure and mechanical properties of Co-based alloy coatings fabricated by laser cladding and plasma arc spray welding," Journal of Alloys and Compounds, vol. 785, pp. 846-854, 2019.

[42] Y. Xiong, Y. Wang, K. F. ZHANG, and G. Q. Zhang, "Microstructures and properties of laser cladding stellite6/WC," China Surface Engineering, no. 1, pp. 37-40, 2008.

[43] N. T.-H. Pham and V.-T. Nguyen, "Behaviour of TiC particles on the Co50-based coatings by laser cladding: morphological characteristics and growth mechanism," Advances in Materials Science and Engineering, vol. 2020, Article ID 8462607, 16 pages, 2020. 